\title{
Frequência e Severidade da Disfunção Temporomandibular em Mulheres
} com Migrânea e Migrânea Crônica

Dissertação apresentada à Faculdade de Medicina de Ribeirão Preto da Universidade de São Paulo junto ao Departamento de Biomecânica, Medicina e reabilitação do Aparelho Locomotor, Área de concentração Reabilitação, para obtenção do título de mestre.

Orientadora: Profa. Dra. Débora Bevilaqua Grossi

Co-Orientador: Prof. Dr. Jose Geraldo Speciali

Colaboradoras de Pesquisa: Elaine Regina Teixeira da Silva

Lidiane Lima Florêncio

Thais Cristina Chaves

\section{Ribeirão Preto}


AUTORIZO A REPRODUÇÃO E DVULGAÇÃO TOTAL OU PARCIAL DESTE TRABALHO, POR QUALQUER MEIO CONVENCIONAL OU ELETRÔNICO, PARA FINS DE ESTUDO E PESQUISA, DESDE QUE CITADA A FONTE.

Ficha Catalográfica

Gonçalves, Maria Claudia

Frequência e Severidade da Disfunção Temporomandibular em Mulheres com Migrânea e Migrânea Crônica. Ribeirão Preto, 2010.

61p. il., $30 \mathrm{~cm}$.

Dissertação apresentada à Faculdade de Medicina de Ribeirão Preto da Universidade de São Paulo/USP - Programa de Pós-Graduação Ciências da Saúde Aplicadas ao Aparelho Locomotor., Área de concentração: Reabilitação.

1. Disfunção temporomandibulara, 2. Migrânea, 3. Severidade, 4. Dor orofacial, 5. RDC/TMD, 6. Índice Anamnésico de Fonseca, 7. Dor Crônica. 
FOLHA DE APROVAÇÃO

Maria Claudia Gonçalves

\section{Frequência e Severidade da Disfunção temporomandibular em Mulheres com Migrânea e Migrânea Crônica}

Dissertação apresentada à Faculdade de Medicina de Ribeirão Preto da Universidade de São Paulo junto ao Departamento de Biomecânica, Medicina e reabilitação do Aparelho Locomotor, Área de concentração: Reabilitação. Para obtenção do título de mestre.

Aprovado em:

Banca Examinadora

Profa Dra : Débora Bevilaqua Grossi

Instituição: Curso de Fisioterapia - Faculdade de Medicina de Ribeirão Preto - USP

Assinatura:

Prof Dr : José Geraldo Speciali

Instituição: Departamento de Neurologia - Faculdade de Medicina de Ribeirão Preto - USP Assinatura:

Profa Dra Simone Cecílio Hallak Regalo

Instituição: Depto. De Morfologia, Estomatologia e Fisiologia - faculdade de Odontologia - USP Assinatura: 
Este trabalho é dedicado a minha mãe que mesmo sem entender o que eu "tanto estudava" me apoiou e se alegrou com as minhas conquistas, pela sua dedicação incondicional a nossa família e por sua sabedoria de acreditar que nada é impossível. Dedico também este trabalho a minha querida amiga Claudinan que em todos os momentos de incerteza e aflição esteve ao meu lado, por não me deixar desistir mesmo quando tudo parecia perdido, por me mostrar que sou capaz e nem pior nem melhor que as outras pessoas e aos meus tios J osé Carlos e Djanira e Geraldo e Fátima que me incentivaram através de seus exemplos desde o inicio dos meus estudos até a concretização dessa dissertação. 
Nem olhos viram, nem ouvidos ouviram, nem jamais penetrou em coração humano o que Deus tem preparado para aqueles que o ama. É Deus quem opera em nós tanto o querer como o efetuar, segundo sua boa vontade. Querido Deus, não tenho palavras para agradecer sua bondade, dia após dia me cercas com fidelidade, nunca me deixe esquecer que tudo que tenho, tudo que sou e o que vier a ser, vem de ti Senhor.

Agradeço a minha mãe e meu pai, Itelvina e José, que se esforçaram muito para que eu estudasse e alcançasse um futuro melhor que o deles, que se alegraram com as minhas conquistas e me apoiaram em decisões difíceis como a de ir para um lugar sem saber onde morar ou como me manter. Obrigado mamãe pela sua coragem, firmeza emocional e por confiar em mim.

Ao meu irmão Antonio Marcos, que sempre esteve ao lado dos nossos pais. Que viu e sofreu de perto todas as mudanças desses últimos onze anos que estou fora de casa. Sobretudo esses últimos cinco anos em que tantas coisas difíceis aconteceram. Obrigada por se manter junto aos nossos pais, me conforta saber que você os vigia de perto.

Ao meu estimado professor Cláudio Monteiro da Cruz, homem sincero e integro em sua fé que me ensinou a amar nossa profissão e a compreender que Deus é sempre o mesmo e nada posso fazer para que ele me ame menos ou mais do que já ama.

Aos professores Cláudio e Marianita Nery que me receberam com dedicação de mestres quando nem eu sabia direito o que fazer. Obrigada por me receberem em sua casa, por me cederem espaço em seus consultórios, por acreditarem na minha força de vontade e na minha capacidade.

Ao Prof Dr José Geraldo Speciali que conseguiu identificar minhas necessidades e quem realmente poderia supri-las, por abrir espaço em seu ambulatório e em sua rotina para nos ajudar a desenvolver nossos trabalhos e por aceitar fazer parte da minha banca de dissertação contribuindo ainda mais para o meu conhecimento e aprendizado.

A minha estimada orientadora Profa Dra Débora Bevilaqua-Grossi que não apenas me orientou neste trabalho, mas permitiu que eu fizesse parte dos seus sonhos e conquistas e participou inteiramente dos meus, que me recebeu com paciência e me conduziu pelas mãos, que reconheceu e respeitou minhas limitações e com elas me ajudou a fazer degraus para alcançar o que temos hoje. Pela mulher sábia, mãe carinhosa e professora dedicada obrigada por confiar em mim e permitir que eu desenvolvesse esse trabalho junto com você.

Agradeço a Profa Dra Anamaria Siriani de Oliveira pelas palavras de apoio e conforto, pelos momentos de alegria e descontração que tornam nossos dias mais prazerosos. Obrigada pelas correções sempre necessárias a minha formação e por desejar que sejamos cada vez melhores.

Agradeço a profa dra Simone Regalo da FORP, por tão gentilmente aceitar contribuir com nosso trabalho e estar presente em um momento tão importante de minha vida. 
Como não poderia deixar de mencionar, agradeço a minha querida “irmã" Profa Dra Adriane da Silveira Gomes, em quem me espelhei para vir a Ribeirão Preto e fazer esse mestrado. Obrigada amiga pelo o carinho e incentivo, por me mostrar que apesar de ser mais difícil, pessoas de origem tão simples podem sim alcançar as alturas. Agradeço também a amiga Profa Dra Lílian Sibele pelo incentivo e doçura que tanto me ajudaram e também pelas orações que trouxeram conforto e direcionamento a minha alma.

Agradeço minhas amigas de republica Profa Dra Ana Carolina (pelo exemplo constante de disciplina e dedicação), Profa Mislene (por sua generosidade), Marcinha (por provar que primeiro devemos buscar o Reino de Deus e as demais coisas nos serão acrescentadas), Profa Luciana (por sua perseverança e bondade) e Jacqueline (pela alegria e companhia que sempre me deu e pelo carinho que sua família me recebeu). Pedras preciosas que Deus colocou em meu caminho para formar um vale onde fui protegida e incentivada através dos exemplos de cada uma. Obrigada amigas por todas as conversas e por todos os almoços que tanto me alegraram.

Agradeço a todas os meus amigos e colegas que de alguma forma contribuíram para a conclusão desse trabalho.

Querida amiga Claudinan Pereira Farias, a Bíblia diz que "há amigos mais chegados que a um irmão”. Obrigada por ser verdadeiramente minha amiga, por estar sempre disponível para ajudar a minha família em momentos em que eu não pude estar presente, por não medir esforços para estar conosco principalmente nos momentos mais difíceis, pela sua perseverança, incentivo e confiança de que Deus esta sempre agindo, mesmo que seja em silêncio.

Agradeço a grande família do Laboratório da Analise da Postura e do Movimento Humano - LAPOMH, obrigada por me deixarem fazer parte de seus desafios e conquistas. Agradeço aos meus companheiros e amigos de pós-graduação: Marcelo Saad e Rogério (pelo carinho e capacidade de me fazer sorrir e saber aproveitar o bom da vida), Letícia Melo (por me ajudar a lidar com a pesquisa e com os sentimentos humanos) Jaqueline Martins (pela leveza e doçura que transmite a todos nós), Profa Lílian Ramiro (pela amizade, carinho e conselhos sempre certos, hoje sei que sua inspiração vem do Espírito Santo), Profa Dra Thais Cristina Chaves (obrigada pela atenção e ajuda, principalmente quando eu não tinha a mínima idéia de como prosseguir e você me clareou o caminho) Michelle Tanure (por permitir que eu compartilhasse meus medos e incertezas) Prof Daniel Coelho (obrigada por me divertir e socorrer, é muito bom poder contar com você no CER), Profa Helga (pela alegria, força e desprendimento em ajudar seu semelhante) Agradeço também aos colegas Guilherme Barbosa, Guilherme Sposito, Amanda Fusaro, Denise Iunes, Ana Paula, Algusto Baffa e Rodrigo que de alguma forma contribuíram para o término desse trabalho.

Agradeço muitíssimo as alunas do curso Fisioterapia da FMRP, Lidiane Lima e Elaine Regina, sempre dispostas a me ajudar nas coletas e a resolver problemas, mesmo que pessoais. Agradeço a Deus por ter escolhido vocês para me ajudarem nessa jornada nem sempre fácil, vocês também fazem parte desse trabalho. Agradeço também as aluna Alexandra e Vivian por manterem o trabalho em andamento, quando precisei me ausentar, garantindo nosso espaço no ambulatório de cefaléia, Patrícia pela ajuda nas coletas, Kátia Pegorette pela torcida e pensamento crítico que me fizeram avaliar o que eu realmente queria. 
Agradeço as funcionárias Lucimaura e Alexandra pela companhia e por compartilhar comigo suas horas de almoço. Momentos de confidências em que eu pude me abrir e contar com um conselho amigo. Obrigada meninas é bom poder contar com a amizade de vocês diariamente. Agradeço também a Vanessa por atender com paciência e dedicação aos meus pedidos constantes e a Dona soninha por responder aos meus infindáveis pedidos de caronas.

Agradeço de todo coração aos membros Igreja Presbiteriana do Brasil - Ebenezer - por me acolher como família e me suprir não apenas nas necessidades espirituais, mas, também nas necessidades mais básicas como alimentação e vestuário. Obrigado Pastor Rubens, Elenita e toda a sua familia por me ensinar que servir a Deus exige dedicação tanto a palavra de Deus como ao próximo; agradeço aos membros em especial dona Anésia “cabecinha de cotonete”, Aldinha, Pedro, Antonieta, Alex, Vera, Joval, Claudete, Rejane e Michael obrigada por toda ajuda e incentivo. Agradeço também a todos da UMP - União da Mocidade Presbiteriana - é mesmo um presente de Deus poder servi-lo ao lado de vocês.

Agradeço aos membros da Igreja Videira que freqüentei no primeiro ano que passei em Ribeirão Preto em especial ao Fabrício e a Kely.

Agradeço aos colegas do Ambulatório de Cefaléia: Dra Fabiola Dach, Profa Dra Renata Campi, Profa Myrna, Dra Juliana Stuginsk, Prof Dr Carlos Alberto Bordini, por todo conhecimentos compartilhado. A todos os residentes que passaram pelo ambulatório durante o feitio desse trabalho. Agradeço também ao colega Thiago do nascimento por me recobrar as esperanças em um momento em que tudo realmente estava perdido, você tinha razão o “copo estava meio cheio”.

Agradeço as pacientes do ambulatório de cefaleia que prontamente aceitaram o convite para participar de nossa pesquisa.

Aos professores e funcionários do Departamento de Biomecânica, Ortopedia e Reabilitação do Aparelho Locomotor por nos ensinar e servir com tamanha dedicação, principalmente em meus momentos de confusão e no limite do prazo quando eu deixava minha “artéria dramática” falar mais alto. Agradeço também a todas as secretárias da pós-graduação da FMRP-USP por ajudar e sanar as dúvidas por mais repetitivas que elas fossem.

Agradeço ao CEMEQ - Centro de Métodos Quantitativos - por realizar parte das Ánalises Estatísticas deste trabalho.

Agradeço a FAPESP - Fundação de Amparo á Pesquisa do Estado de São Paulo - Por apoiar financeiramente esse trabalho (processo 2007/57530-0). Agradeço especialmente ao meu assessor que acreditou que esse trabalho era uma boa proposta e que poderia ser desenvolvido. 

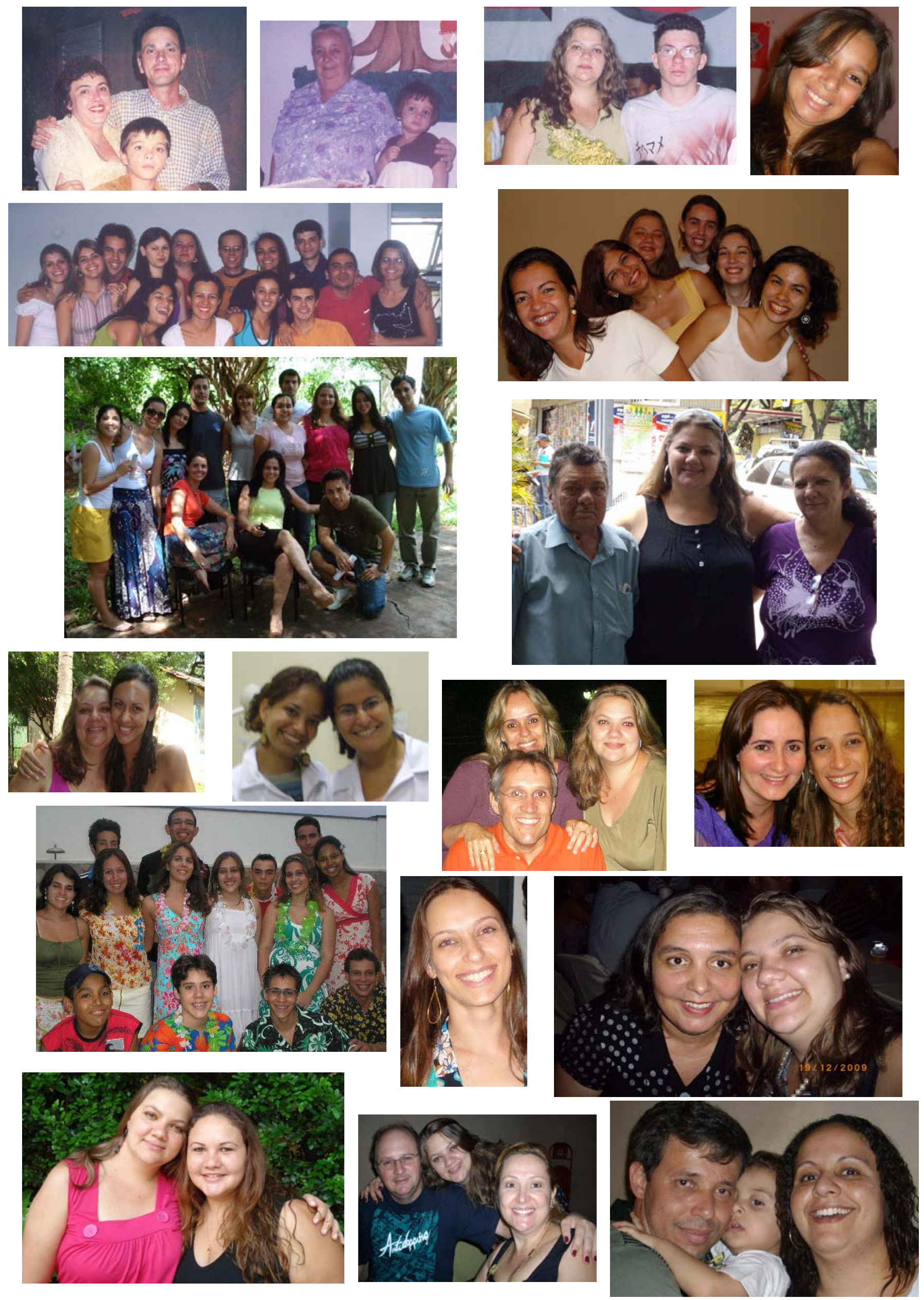


\section{Resumo}

\section{GONCALVES, M.C. Frequência e Severidade da Disfunção Temporomandibular (DTM)}

em Mulheres com Migrânea e Migrânea Crônica. 2010, p.61., Dissertação de Mestrado -

Faculdade de Medicina de Ribeirão Preto da Universidade de São Paulo, Ribeirão Preto.

A Migrânea e a Disfunção Temporomandibular (DTM) são doenças crônicas e tem como aspecto mais importante a dor crônica. Muitos trabalhos descrevem sinais e sintomas de DTM em pacientes com cefaleia sugerindo uma associação entre essas duas condições. Porém, ainda são poucos os trabalhos que utilizaram um critério que fornecesse não apenas sinais e sintomas, mas também a classificação diagnóstica. Assim, o objetivo deste trabalho foi avaliar a frequência da DTM a partir da aplicação do RDC/TMD e a severidade da DTM através do Índice Anamnésico de Fonseca em mulheres com Migrânea, Migrânea Crônica e mulheres sem queixa de cefaleia. Participaram deste estudo 91 mulheres, divididas em três grupos: 30 mulheres no Grupo Controle (GC), 38 mulheres no Grupo Migrânea (GM) e 23 mulheres no Grupo Migrânea Crônica (GMC). As voluntárias dos grupos GM e GMC foram selecionadas durante a primeira consulta no Ambulatório de Cefaleia (ACEF) do Hospital das Clínicas de Ribeirão Preto da Faculdade de Medicina da Universidade de São Paulo e as do GC entre as acompanhantes dos pacientes naquele mesmo dia. Foram inclusas voluntárias com idade entre 18 e 55 anos, que não tivessem ingerido antiinflamatórios e/ou analgésicos nas últimas 24 horas antecedentes à avaliação fisioterapêutica, que não tivesse história de trauma na face, nem usasse prótese dentária parcial ou total e foram excluídas voluntárias com outros tipos de cefaleia e doenças sistêmicas como fibromialgia e artrite reumatóide. Para o $\mathrm{GC}$, as voluntárias não podiam ter queixa de cefaleia nos últimos 3 meses. Três examinadores participaram da coleta. Para análise dos dados foi utilizado a análise da variância (ANOVA two-Way $\mathrm{p}<0,05)$ na comparação dos dados antropométricos e da amplitude de movimento mandibular entre os três grupos e Tukey como post-hoc análise para avaliar a diferença no número de locais dolorosos e o número de diagnósticos, com nível de significância de $(\mathrm{p}<0,05)$. O teste qui-quadrado foi utilizado para verificar a diferença de diagnóstico entre os três grupos e para verificar a freqüência da severidade entre os três grupos foi utilizado o teste exato de Fisher. As voluntárias dos grupos com migrânea apresentaram maior frequência de diagnósticos de DTM em comparação ao $\mathrm{GC}, \mathrm{p}<0,05$ e não foi observada diferença entre os grupos com migrânea. Os diagnósticos, segundo o RDC/TMD, do grupo I (dor miofascial) foram os mais prevalentes nos três grupos estudados e foi mais freqüente nos grupos com migrânea. Os diagnósticos dos grupos I+III estiveram presentes nos três grupos estudados e com maior freqüência no grupo GM. Não foram encontrados diagnósticos individuais pertencentes apenas aos grupos II e III. O número de pontos dolorosos musculares foi significativamente maior nos grupos GM e GMC em relação ao controle e não houve diferença entre os grupos com GM e GMC. As voluntárias dos grupos com migrânea apresentaram maiores graus de severidade de DTM, em comparação ao GC, p<0,05 e o GMC apresentou maior severidade que o GM. Os resultados deste trabalho demonstraram que Mulheres com Migrânea tem maior frequência de DTM, apresentam maior número de diagnósticos e de pontos dolorosos segundo o RDC/TMD que mulheres sem migrânea bem como maiores graus de severidade de DTM. Portanto a DTM e a Migrânea estão clinicamente relacionadas.

Palavras-Chave: Disfunção temporomandibular, Migrânea, Severidade, Dor orofacial, RDC/TMD, Índice Anamnésico de Fonseca, Dor Crônica. 


\begin{abstract}
GONCALVES, MC Frequency and Severity of Temporomandibular Disorders (TMD)

in Women with Migraine and Chronic Migraine. 2010 p.61., Master Thesis - Faculty of

Medicine of Ribeirão Preto, University of São Paulo, Ribeirão Preto
\end{abstract}

Migraine and Temporomandibular Disorders (TMD) are chronic disorders and their most important aspect is the chronic pain. The persistent cranial-cervical and orofacial pain is the predominant reason why people seek treatment. Besides the pain, the affected areas are also similar suggesting an association between these two conditions. Many studies describe signs and symptoms of TMD in patients with headache suggesting an association between these two conditions. However, there are few studies that use a criterion that provides not only signs and symptoms, but also the diagnostic classification. The Diagnostic Criteria for Research in Temporomandibular disorders (RDC / TMD) provide a diagnostic classification with reports of acceptable levels of reliability, provide specifications for the conduct of a clinical standard and allow the development of clinical diagnoses (Axis I), the classification psychosocial classification of the individual (Axis II). The objective of this study was to evaluate the frequency of the DTM from the application of the RDC / TMD and TMD severity through the history index of Fonseca in women with migraine, chronic migraine and women with complaints of headache. The study included 91 women, divided into three groups: 30 women in the control group (CG), 38 women in the migraine group (GM) and 23 women in Chronic Migraine Group (CMG). The voluntary groups GM and GMC were selected during the first appointment and at the Headache Clinic (ACEF) of the University Hospital of Ribeirão Preto's Faculty of Medicine, (University of São Paulo) and the ones of CG were selected among the companions of the patients during that day. There were included volunteers aged between 18 and 55, who had not ingested anti-inflammatory and / or painkillers in the last 24 hours before the physical therapy evaluation and who didn't have a history of face trauma, or wore partial or total dentures and volunteers with other types of headache and systemic diseases such as fibromyalgia and rheumatoid arthritis were excluded. For the GC, the volunteers could not have complained of headache in the last 3 months. Three examiners participated in data collection, I and II in the initial screening of volunteers and III in the implementation of the RDC / TMD and the history index of Fonseca, the examiner III was blind to the conditions of the volunteers and was previously trained. In order to analyze the Data it was used analysis of variance (two-way ANOVA $p<0.05$ ) in comparison of anthropometric data and range of mandibular movement between groups and Tukey as posthoc analysis to evaluate the difference in the number of painful sites and the number of diagnoses, with a significance level of $p<0.05$. The chi-square test was used to determine the difference in diagnosis between the three groups and to determine the frequency of severity among the three groups used the Fisher exact test. The voluntary group with migraine showed a higher frequency of diagnosis and higher severity of TMD in comparison to the CG, $p<0.05$ and no difference was observed between the groups with migraine.

Key-Words: Temporomandibular disorders, Migraine, Severity, Orofacial pain, RDC/TMD, Index Anamnésico de Fonseca, Chronic pain. 


\section{Lista de abreviaturas e siglas}

ACEF

ATM

CCD

CTT

CTTC

CTTE

DTM

$\mathrm{GC}$

GM

GMC

ICHD

IHS

MAB

MABA

MABP

SNC

$\mathrm{n}$
Ambulatório de Cefaleia

Articulação Temporomandibular

Cefaleia Crônica Diária

Cefaleia do Tipo Tensional

Cefaleia do Tipo Tensional Crônica

Cefaleia do Tipo Tensional Episódica

Disfunção Temporomandibular

Grupo Controle

Grupo Migrânea

Grupo Migrânea Crônica

International Classification of Headache Disorders

International Headache Society

Máxima Abertura da Boca

Máxima Abertura da Boca Ativa

Máxima Abertura da Boca Passiva

Sistema Nervoso Central

Número 


\section{Lista de figuras}

Figura 1 - Demonstração da mensuração da amplitude de movimento mandibular utilizando o paquímetro

Figura 2 - Demonstração da estabilização contra lateral da cabeça do voluntário

Figura 3 - $\quad$ Palpação manual do fascículo anterior do músculo temporal. 33

Figura 4 - $\quad$ Palpação manual do fascículo médio do músculo temporal 33

Figura 5 - $\quad$ Palpação manual do fascículo posterior do músculo temporal 33

Figura 6 - Palpação manual da origem do músculo masseter. 33

Figura 7 - Palpação manual do ventre do músculo masseter. 33

Figura 8 - Palpação manual da inserção do músculo masseter. 33

Figura 9 - $\quad$ Palpação manual da região posterior da mandíbula 34

Figura 10 - Palpação manual da origem da região submandibular. 34

Figura 11 - Palpação manual do pólo lateral da ATM ............................................ 34

Figura 12 - Palpação manual do pólo posterior da ATM......................................... 34

Figura 13 - Palpação intra oral da região da cabeça lateral do músculo pterigóideo lateral 


\section{Sumário}

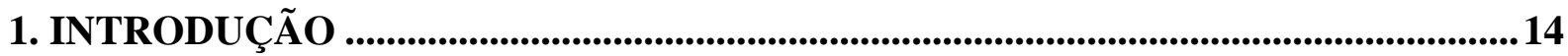

1.1. Definição e Epidemiologia da Migrânea ....................................................................... 14

1.2. Manifestações Clínicas e fisiopatologia da Migrânea ................................................. 15

1.3. Definição e Epidemiologia da Disfunção Temporomandibular ................................... 17

1.4. Avaliação da Disfunção Temporomandibular ................................................................... 18

1.5. Correlações entre Cefaleia e Disfunção Temporomandibular ......................................21

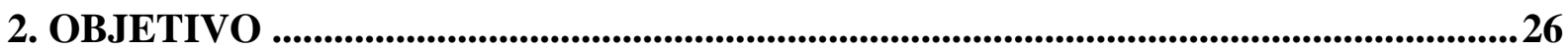

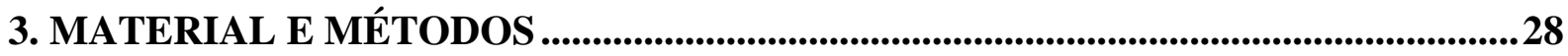

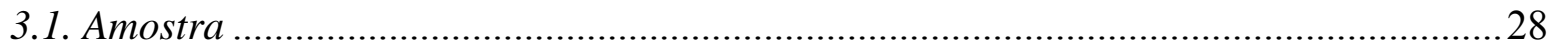

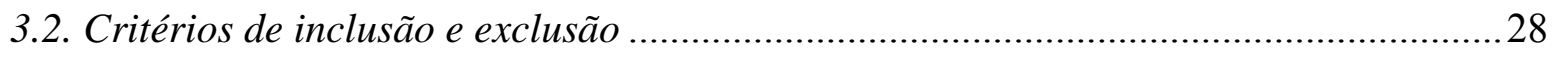

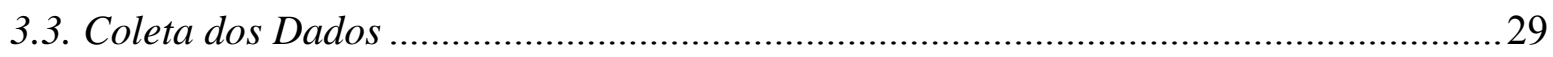

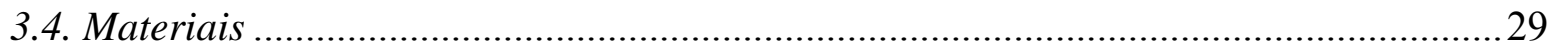

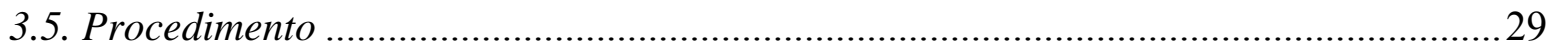

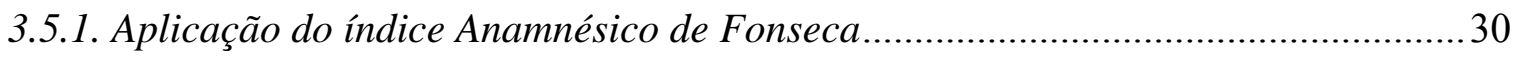

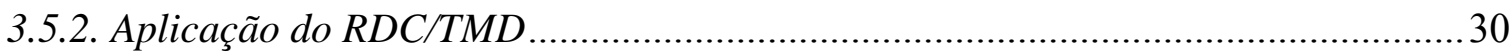

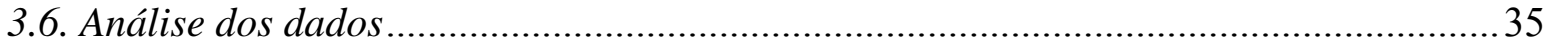

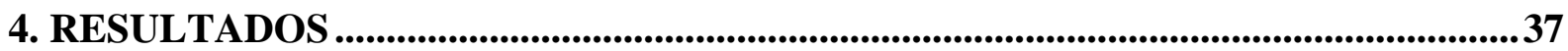

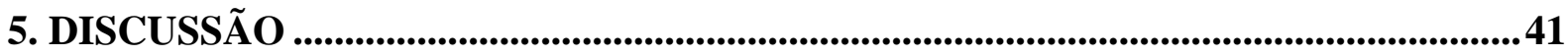

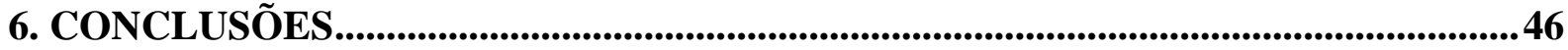

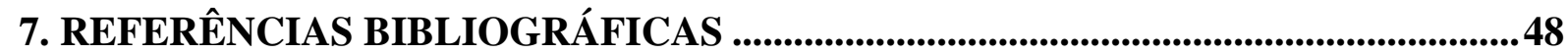

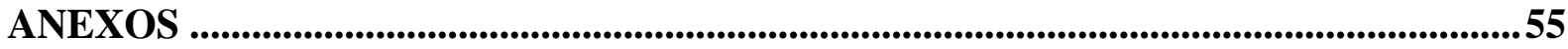




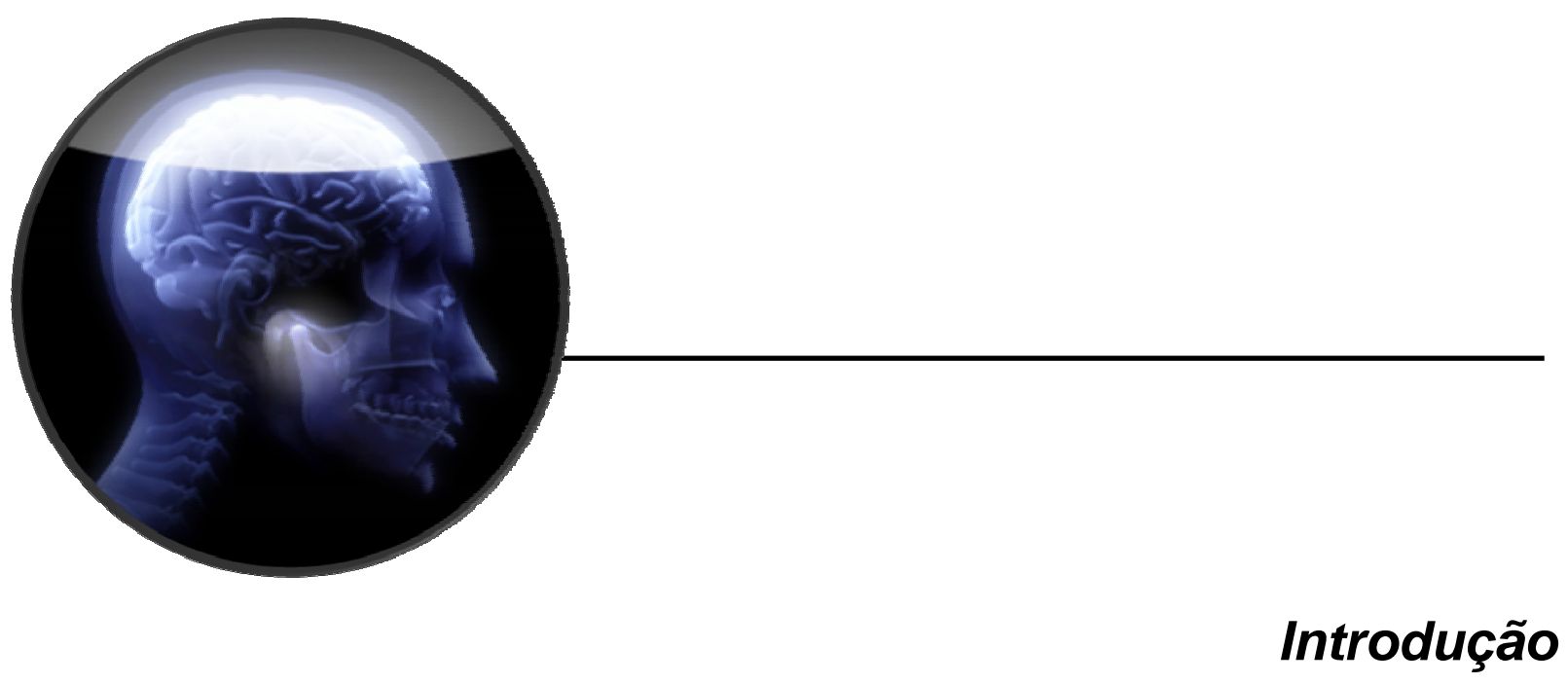

"O temor do Senhor é o princípio da sabedoria; Revelam prudência todos que a praticam". Salmo, cap.111, v. 10. 


\section{INTRODUÇÃO}

\subsection{Definição e Epidemiologia da Migrânea}

A cefaleia é um sintoma altamente prevalente na população. Estima-se que $76 \%$ das mulheres e $57 \%$ dos homens tenham pelo menos um episódio de cefaleia por mês. As cefaleias primárias mais prevalentes na população geral são as cefaleias do tipo tensional (CTT) que acomete cerca de $69 \%$ da população, em sua forma episódica (CTTE) e crônica (CTTC) (RASMUSSEN, 1995). Em relação à migrânea (enxaqueca), estima-se que pelo menos $3 \%$ a $6 \%$ dos homens e $13 \%$ a $18 \%$ das mulheres a apresentem (SILBERESTEIN e LIPTON, 1996; LIPTON; SILBERESTEIN; STEWART, 1994).

A migrânea acomete cerca de $18 \%$ das mulheres e $6 \%$ dos homens americanos, é mais comum durantes os anos mais produtivos do indivíduo, entre 25 e 55 anos, acomete 3 vezes mais mulheres do que homens (LIPTON;BIGAL, 2007; STOVNER et al., 2007) e está diretamente relacionada com o status socioeconômico (LIPTON;BIGAL, 2007).

A migrânea é uma cefaleia crônica recorrente, manifestada por crises de duração de 4 a 72 horas; com intensidade moderada ou forte, de localização unilateral, de característica pulsátil, piorando com o esforço e acompanhada por náusea, vômito, fonofobia e/ou fotofobia. Pode ser classificada como migrânea com aura e como migrânea sem aura (CIC, 2004),

Antes dos 12 anos de idade, a migrânea é mais comum em meninos que meninas. Essa relação se inverte a partir da adolescência e a preponderância feminina (relação mulher/homem) é de 2:1 aos 20 anos de idade e 3,3:1 aos 40 anos. Mesmo após a menopausa o predomínio feminino permanece (RASMUSSEN et al., 1991, RASMUSSEN, 1995).

A migrânea começa como uma doença episódica, ou seja com menos de 15 dias de crises por mês, porém pode se cronificar passando a ocorrer mais de 15 dias por mês. Estimase que $3 \%$ dos sofredores de cefaleia evoluam para cefaleia crônica diária (CCD), essa porcentagem e de $14 \%$ entre os sofredores de migrânea especificamente (KATSARAVA et al., 2004).

A cefaleia crônica diária (CCD) ocorre 15 dias ou mais dias por mês e afeta cerca de $4 \%$ da população geral. A migrânea crônica é um subtipo da $\mathrm{CCD}$, possui as mesmas características da migrânea é uma conseqüência da progressão da migrânea e sua prevalência é de $\%$ (CASTILHO et al., 1999). 
Entre os fatores de risco para progressão da migrânea estão incluídos, a alta freqüência das crises, o abuso de analgésicos e antiinflamatórios, obesidade, tabagismo, excesso de cafeína e fatores estressantes da vida diária (SCHER et al., 2003; BAHARA et al., 2003).

\subsection{Manifestações Clínicas e fisiopatologia da Migrânea}

A crise de migrânea tem 5 fases: sintomas premonitórios ou de pródromo, aura, cefaleia, sintomas associados e o período de resolução da crise ou posdrómo.

- Fase 1 - pródromo: esta fase precede ao aparecimento da dor em algumas horas ou até um dia. Nesta fase o paciente fica mais irritadiço, com raciocínio e memorização mais lentos, tem desejo por doces e o sono é agitado, com pesadelos e distúrbios do sistema digestivo. Diarréia, poliúria, apatia, irritabilidade, dificuldade de concentração, sudorese e visão borrada são também relatos. Cerca de $60 \%$ dos migranosos tem sintomas premonitórios (SILBERSTEIN et al., 1996).

O pródromo é provocado por distúrbios límbico-hipotalamicos, nos locais onde predominam uma hipersensibilidade dopaminérgica (SPECIALI, 2003).

- Fase 2 - aura: consiste de sintomas oriundos do sistema nervoso central (SNC), com duração média de 5 a 20 minutos (máximo de uma hora) e pode anteceder a dor, acompanhá la ou surgir como manifestação isolada da crise. Pode se expressar por sintomas visuais e ocorrem em cerca de 15\% das crises (fosfenos, pontos luminosos, zig-zags, quadrantopsias, teicopsias, espectros de fortificação, macro e micropsias, mudanças de cor e forma dos objetos). Muitas vezes os sintomas de aura são sensitivos e mais complexos surgindo hemiparaestesias, hemiparesias, distúrbios da fala ou sintomas relacionados ao tronco cerebral. Cerca de $82,9 \%$ dos migranosos com aura tem algum sintoma visual e $4,8 \%$ tem sintomas visuais e sensitivos (FARIAS DA SILVA, 1998).

A aura é causada por uma depressão alastrante da atividade cortical que propaga uma onda a partir do pólo occiptal com conseqüente hipoperfusão sanguínea de variados graus e duração. Esta fase esta relacionada a noradrenalina, distúrbios dos canais de cálcio e deficiência de magnésio (CUTRER, 2009).

- Fase 3 - Cefaleia: a duração da fase da dor é de 4 a 72 horas, se não for tratada. A fase da cefaleia é o aspecto de maior destaque dentro do quadro sintomatológico da migrânea, A cefaleia tem seu inicio insidiosamente, instala-se crescendo de intensidade, atinge um máximo e diminui lentamente. A cefaleia também pode se instalar subtamente ou despertar o indíviduo no sono. É unilateral no início, em cerca de 50\% a 75\% dos casos, podendo se 
tornar difusa no desenrolar da crise. O caráter pulsátil está quase sempre presente, piora com as atividades diárias, necessitando ir para a cama, em lugar escuro e silencioso. A intensidade pode variar, mais frequentemente vai de moderada a forte (BORDINI, 1998).

A fase de cefaleia deve-se a ativação do sistema trigemino-vascular, resultando em reação inflamatória estéril no espaço perivascular das meninges. Após o pródromo e a aura, que nem sempre estão presentes em uma crise de migrânea, há ativação do núcleo do trigêmeo, especialmente dos neurônios do primeiro ramo, resultando em estímulos que caminham para a periferia, especialmente para os vasos da meninge, local onde são liberados neurotransmissores que agem nos vasos provocando vasodilatação e aumento da permeabilidade vascular (GOADSBY; EDVINSSON, 1993). A abertura dos poros vasculares permite extravasamento de plasma e substâncias endovasculares que promoverão uma inflamação. A estimulação das aferências nociceptivas trigeminais provocada pela estimulação, gerará estímulos algógenos que serão levados ao núcleo trigeminal e daí para o tálamo e finalmente ao córtex onde a dor se tornará consciente (SILBERSTEIN; LIPTON; GOADSBY, 1998).

- Fase 4 - sintomas associados: surgem durante ou depois do início da cefaleia e são caracterizados por fonofobia, fotofobia, osmofobia, náuseas e vômitos, palidez cutânea, hiperemia conjuntival, obstrução nasal, rinorréia e anorexia. Náuseas e/ou vômitos aparecem geralmente no final da fase de cefaleia (SPECIALI , 2003).

Os mecanismos fisiopatológicos dos sintomas associados não estão suficientemente elucidados, mas a ativação dos núcleos vagais e dos sistemas sensoriais, com certeza estão envolvidas nessa fase da crise migranosa (RASKIN, 1998).

- Fase 5 - Pósdromo: nesta última fase, há sensação de letargia e exautão, os pacientes ficam horas ou até dias com sensação de cansaço, fraqueza, como se tivessem disputado uma maratona, necessitando de um período de repouso para a completa recuperação, algumas vezes com depressão outras com euforia. O pródromo assim como os sintomas associados, ainda não estão bem compreendidos e poderão ser explicado por mecanismos de exaustão ou inibição ativa do processo migranoso (SPECIALI, 2003).

Uma crise de migrânea, portanto pode durar dois ou mais dias e durante esse período o paciente fica total ou parcialmente incapacitado para exercer suas atividades diárias.

Atualmente a teoria melhor aceita como causa etiológica da migrânea é que os pacientes possuam um encéfalo hiperexcitável, sendo que a hiperexcitabilidade é herdada. Possivelmente a hiperexcitabilidade cortical seja conseqüência da diminuição do íon magnésio encefálico, aumento de aminoácidos excitatório, como aspartato e glutamato, e 
alterações dos canais de cálcio. Fatores precipitantes, como estresse, menstruação, ingestão de alguns alimentos específicos, luz e odores fortes, iniciariam a deflagração de uma crise de migrânea (WELCH, 1993; WEILLER et al., 1995). Assim, situações comuns do dia a dia podem desencadear uma cascata de eventos que culminam com a crise de migrânea.

\subsection{Definição e Epidemiologia da Disfunção Temporomandibular}

Disfunção Temporomandibular (DTM) é um termo coletivo que envolve todas as condições relativas a Articulação Temporomandibular (ATM) e estruturas do sistema estomatognático ou mastigatórios associadas (ASTJS,2003). A DTM se refere a um aglomerado de desordens caracterizadas por ruídos articulares, limitação na amplitude de movimento ou desvios durante a função mandibular, que são considerados como sinais de DTM, e dor pré-auricular, dor na ATM ou nos músculos mastigatórios, caracterizados como sintomas (DWOKIN et al., 1990).

As DTMs são consideradas uma subclassificação das desordens músculo-esqueléticas (OKESON, 1998) e tipicamente tem um curso recorrente ou crônico, com períodos de flutuação dos sinais e sintomas de DTM ao longo do tempo (MAGNUSSON; EGERMARK; CARLSSON, 2000).

A DTM é uma das condições de dor orofacial e pode ser subdividida em duas categorias: desordens da ATM ou artrogênicas (deslocamentos de disco com ou sem redução, luxação articular e desordens inflamatórias) e desordens dos músculos mastigatórios ou miogênicas (miosites, disfunção dolorosa miofascial, mioespasmo e neoplasmas (OKESON, 1998).

A etiologia da DTM é multifatorial (OLIVEIRA et al., 2003), entre os fatores etiológicos estão, traumas da mandíbula ou ATM, maloclusão e interferências oclusais, alterações nos músculos mastigatórios, microtraumas causados pelos hábitos parafuncionais, condições reumáticas, estresse emocional, ansiedade e anormalidades posturais (VISSCHER ET AL., 2001; PEDRONI; OLIVEIRA; GUARATTNI, 2003). Cerca de 75\% da população tem pelo menos um sinal de DTM e 33\% tem pelo menos um sintoma de DTM (MANNHEIMER; ROSENTHAL,1991).

Sua prevalente é maior em mulheres, $80 \%$ dos pacientes que procuram tratamento são do sexo feminino com idade entre 20 a 40 anos (LERESCHE, 1997). Nestas as DTMs manifestam-se normalmente por um ou mais dos seguintes sinais e sintomas: dor na região orofacial, normalmente agravada por mastigação ou outras funções do sistema 
estomatognático, limitação no movimento mandibular, sons ou estalidos no movimento articular (SARLANI, 2003). Outros sinais e sintomas afetam a região do crânio e do pescoço como cefaleia, dor na região cervical, e aqueles relacionados á orelha como zumbido e otalgia (OLIVO et al., 2006).

\subsection{Avaliação da Disfunção Temporomandibular}

Para se avaliar portadores de DTM é importante a utilização de ferramentas válidas, sensíveis e confiáveis, que avalie o maior número possível de sinais e sintomas (OLIVEIRA et al., 2003).

Existe na literatura cliníca muitos trabalhos descrevendo os sinais e sintomas para a DTM (GREENE; MARBACH, 1982; RUGH; SOLBERG, 1985; DWORKIN et al ., 1990; FRICTON, 1991).Vários instrumentos para avaliação de DTM têm sido propostos e os mesmos estão organizados de diversas formas, questionários, índices anamnésicos e clínicos e critérios diagnósticos.

O primeiro índice clínico desenvolvido para avaliação objetiva da DTM foi o índice de Helkimo (HELKIMO, 1974), que é constituído de duas partes, Índice de disfunção anamnésica e Índice de disfunção clínica. A soma dos pontos obtidos em cada um fornece uma pontuação final que permite classificar o paciente como portador de DTM leve, moderada, grave, ou ainda como DTM ausente.

O índice de Helkimo apresenta limitações, como não fornecer classificação diagnóstica, mas apenas avaliação de severidade de sinais e sintomas, opondo-se às tendências atuais na área de DTM, em que preconiza a abordagem diagnóstica. Outra limitação é seu sistema de pontuação, apenas o voluntário que apresentar ausência total de sinais e sintomas é classificado como assintomático (VAN DER WEELE et al., 1986). Assim, existe uma grande possibilidade de classificar um voluntário saudável em algum grau de severidade do índice (CHAVES et al 2008).

O Questionário e Índice Anamnésico de Fonseca foi elaborado nos moldes do índice anamnésico de Helkimo (1974) e é um dos poucos instrumentos disponíveis em língua portuguesa para caracterização da severidade dos sintomas de DTM. Este questionário foi previamente testado em pacientes com DTM e demonstrou uma correlação de $95 \%$ com o índice clínico de Helkimo. Para cada uma das questões do questionário de Fonseca são possíveis três respostas (sim, não e às vezes) que recebem as pontuações de $(10,0$ e 5 
respectivamente). Somando se os pontos, pode-se classificar os voluntários em categorias de severidade de sintomas, sem DTM, DTM leve, moderada ou severa (FONSECA, 1994).

Em 1992 Dworkin \& LeResche, desenvolveram o Critério de Diagnóstico para Pesquisa em Disfunção Temporomandibular (RDC/TMD). Este é um dos instrumentos diagnósticos mais amplamente utilizados e aceitos e para o qual foram relatados níveis de confiabilidade aceitáveis. O RDC/TMD foi formalmente traduzido para 18 idiomas (JOHN 2005), incluindo o português.

Um obstáculo crítico para o conhecimento da DTM era a falta de um critério diagnóstico padronizado para definir subtipos clínicos da disfunção. O RDC/TMD corrige essa falha uma vez que agrupa um conjunto de critérios diagnósticos para pesquisa, visando permitir padronização e replicação da pesquisa sobre formas etiológicas mais comuns da DTM (miogênica e artrogênica) (CHAVES et al., 2008).

O RDC/TMD fornece especificações para a condução de um exame clínico padronizado e permite a elaboração de diagnósticos clínicos (Eixo I), baseados em achados do exame e em poucas questões para auto-relato que se referem primariamente à presença e localização de dor. Permite também a classificação psicossocial do sujeito (Eixo II) baseado em instrumentos psicométricos padronizados que permitem a graduação do status da dor crônica, graduação da depressão, graduação dos níveis de sintomas físicos não específicos e graduação resumida das limitações durante função mandibular. A força do RDC/TMD é dupla, primeiro porque promove um critério padronizado que contém um diagnóstico acurado das DTMs de maneira fácil e com replicação confiável para clínicos e pesquisadores, alem do mais ele não foca somente o componente físico da DTM mas fornece uma maior compreensão das DTMs com uma classificação de sistemas multiaxiais (MANFREDINI et al., 2004).

O eixo I avalia a mobilidade articular (abertura, desvio lateral e protrusão), bem como a palpação de 16 pontos musculares cujo acesso é extra oral (temporal posterior direito e esquerdo, temporal médio direito e esquerdo, temporal anterior direito e esquerdo; masseter origem direito e esquerdo, masseter ventre direito e esquerdo, masseter inserção direito e esquerdo; região mandibular posterior direita e esquerda, região submandibular direita e esquerda) e mais 4 pontos de acesso intra-oral (area do pterigóide lateral direito e esquerdo e tendão do temporal direito e esquerdo). Também são palpados o polo lateral da ATM e a região posterior dessa articulação. Totalizando 24 pontos. A palpação dos pontos dolorosos é realizada atraves de digito-pressão, Segundo Visscher et al (2004), a habilidade da palpação em descriminar pessoas com queixas de DTM de indivíduos sem dor é comparável à algometria. No eixo I ainda está incluída a verificação de sons articulares durante os 
movimentos mandibulares (RAMMELSBERG et al., 2003). A verificação desses sons é feita por meio da palpação manual. Segundo Dworkin et al., (1990), a verificação dos sons articulares pela palpação é tão confiável quanto a realização com estetoscópio.

O RDC/TMD ainda vem acompanhado de uma série de instruções verbais para serem empregadas durante o exame físico (LOBBEZO et al., 2005 ). Esses comandos são utilizados para avaliar padrão de abertura (“Eu gostaria que você abrisse sua boca o máximo que puder, mesmo que você sinta um pequeno incomodo"), para determinar ruídos articulares ("Enquando eu estiver com os dedos embaixo da sua articulacão eu gostaria que vc lentamente abrisse o máximo que consegue e então lentamente fechasse a boca”), e para determinar pontos dolorosos ("Agora eu vou palpar dentro da sua boca, enquanto eu estiver palpando, gostaria que você mantivesse sua mandíbula relaxada”) (DWORKIN e LERESCHE, 1992).

Os diagnósticos do eixo I do RDC/TMD são classificados em três grupos. Grupo I grupo das disfunções musculares que compreende a Dor miofascial (Ia) e a Dor miofascial com Limitação de abertura (Ib); Grupo II - grupo das disfunções articulares, compreendendo: deslocamento de disco com redução (IIa), Deslocamento do disco sem redução, com limitação da abertura (IIb) e Deslocamento do disco sem redução, sem limitação da abertura (IIc); e o Grupo III - grupo das disfunções articulares e inflamatórias, Artrite (IIIa), Osteoartrite (IIIb) e Osteoartrose (IIIc). De acordo com os achados durante a aplicação do eixo I do RDC/TMD o paciente pode receber até cinco diagnósticos, um muscular e até dois articulares por ATM.

RDC/TMD também apresenta algumas limitações. Como se trata de um critério para pesquisa, pacientes com sinais e sintomas clinicamente relevantes de DTM podem não se enquadrar nas classificações desse critério diagnóstico. Outro aspecto é a falta de evidência científica para alguns critérios operacionais como a utilização de uma libra (Ib) para palpação manual da ATM e estruturas intra-orais e 2 (Ib) para a palpação das estruturas extra-orais (CHAVES et al., 2008).

No entanto o RDC/TMD é o único sistema de diagnóstico que fornece a descrição detalhada de sua obtenção, e ainda, por se tratar de uma ferramenta biaxial fornece um protocolo de avaliação detalhado que deve ser seguido para efetivação do diagnóstico (eixo I) e um questionário estruturado para avaliação do status psicossocial do paciente com DTM (eixo II) (JOHN et al., 2005). Portanto, quando o objetivo for a obtenção de um diagnóstico, o RDC destaca-se e caracteriza-se como uma das mais bem estruturadas ferramentas disponíveis na literatura para avaliação (CHAVES et al 2008). 


\subsection{Correlações entre Cefaleia e Disfunção Temporomandibular}

Um dos aspectos mais importante tanto da migrânea quanto da DTM é a dor crônica. Dor na região crânio-cervical e orofacial persistente é a razão predominante pela qual indivíduos procuram tratamento. Além da dor, as areas afetadas também são similares sugerindo associação entre essas duas condições.

A associação entre a freqüência dos sintomas de DTM e freqüência de cefaleia foi observada por diversos autores (SCHOKKER et al., 1990; PETTENGILL, 1999; CIACANGLINI; RADAELLI, 2001; VISSCHER et al., 2001b; STORM;WANMAN, 2006) que sugerem que os sintomas são influenciados pelos mesmos fatores contribuintes ou compartilham mecanismos comuns.

Algumas características da DTM, como a duração, a intensidade, e o padrão temporal da dor bem como os distúrbios psicossociais podem ser comparados com pacientes com outras dores crônicas comuns, como a cefaleia, sugerindo que os pacientes com DTM têm uma hiperexcitabilidade do sistema nociceptivo central, que possivelmente contribui para a fisiopatologia da DTM. A sensibilização dos aferentes nociceptivos primários na área afetada, bem como uma hiperexcitabilidade central do sistema trigeminal podem causar a hiperalgesia orofacial (MERRILI, 1997; SARLANI \& GREENSPAN, 2005).

Pacientes com DTM têm uma incidência de migrânea significativamente maior quando comparados a pacientes que buscam tratamento odontológico rotineiro, chegando a ser duas vezes maior nós indivíduos que nunca procuraram esse tipo de tratamento (PETTENGILL CRAIG, 1999). Até mesmo nos estudos em crianças com migrânea, estas tendem a demonstrar mais sinais e sintomas de DTM comparadas a crianças sem migrânea (LILJESTRÖM et al., 2005).

A causa exata da comorbidade entre DTM e cefaleia ainda não é conhecida, mas a sensibilização de mecanismos centrais e periféricos envolvidos na percepção dolorosa poderiam contribuir induzido a distribuição da dor para a região da face e da mandíbula (SARLANI et al., 2005, JOHN et al., 2005).

Ciancaglini e Radaelli (2001) aplicaram o Índice de Disfunção Anamnésico de Helkimo em uma amostra de 483 indivíduos e constataram que sintomas como dor, sons na articulação temporomandibular (ATM) e dor nos movimentos mandibulares estavam associados com cefaleia. Os autores concluíram que a cefaleia ocorre duas vezes mais nos pacientes com DTM que no grupo controle e que cerca de $70 \%$ das pessoas sofrem de cefaleia e DTM conjuntamente. 
Os autores discutem que os desvios anormais da função mandibular podem produzir um estímulo mecânico que provoca mudanças na atividade estomatognática, podendo prolongar a estimulação nociceptiva dos músculos mastigatórios, conduzindo a uma sensibilização nos nociceptores das regiões cranianas e pericranianas, estimulando uma resposta dos neurônios centrais, podendo ser a fonte primária da cefaleia (CIANCAGLINI e RADAELLI, 2001).

Gonçalves et al (2009) realizou um estudo epidemiológico na população de Ribeirão Preto-SP sobre a prevalência de DTM, dos 1230 indivíduos entrevistados, foi constatado que $55,93 \%$ do total tinham queixa de cefaleia. Quando esta foi comparada entre indivíduos com e sem DTM, verificou-se que o relato de cefaleia foi significativamente maior nos indivíduos com DTM, sugerindo que a cefaleia e a DTM são doenças não apenas coincidentes e sim comórbidas, e aproximadamente $75 \%$ dos adultos podem, em algum momento, apresentar sinais ou sintomas dessa síndrome.

DTM e a migrânea são consideradas importantes por várias razões. Primeiro, a DTM pode ser uma causa de cefaleia (cefaleia atribuída a DTM), desordem secundária identificada na classificação Internacional das Cefaleias, $2^{\mathrm{a}}$ Ed. (ICHD-II). Segundo, a DTM pode exacerbar uma cefaleia primária existente e finalmente, os indivíduos com DTM e cefaleia primária (por exemplo migrânea) podem experimentar uma sobrecarga uma vez que mais de um transtorno pode estar esta presente (enxaqueca, cefaleia de DTM, outros sintomas de DTM) (BEVILAQUA-GROSSI., et al, 2009).

Dados populacionais indicam que sintomas de DTM são mais prevalentes em indivíduos com cefaleia do que em indivíduos sem cefaleia. Entre os sofredores de cefaleia, o sintomas de DTM são mais comuns entre os indivíduos com migrânea e CCD em relação a cefaleia do tipo tensional, reforçando a idéia de que a migrânea e a DTM são comorbidas (GONÇALVES,;SPECIALI,; BIGAL, 2009).

A maioria dos estudos diagnosticaram a DTM utilizando a avaliação de sinais e sintomas (SCHOKKER et al., 1990; CIACANGLINE \& RADAELLI, 2001; VISSCHER et al., 2001b) e poucos (GLAROS et al., 2007, BALLEGAARD et al., 2008) trabalhos utilizaram critérios diagnósticos mais elaborados como RDC/TMD em pacientes com cefaleia, um instrumento considerado padrão ouro no diagnóstico das DTMs com confiabilidade e reprodutibilidade já testadas no que diz respeito ao eixo I, e igualmente escassos os que estabeleceram relações entre cefaleia e dados do RDC/TMD.

Entre os autores que aplicaram o RDC/TMD em pacientes com cefaleia, VasquesDelgado., et al (2004) investigaram se pacientes com cefaleia crônica e a DTM apresentam 
diferenças com relação a qualidade do sono e alterações psicológicas como depressão e ansiedade. Avaliaram 67 pacientes com cefaleia crônica diária (CCD), que foram comparados com 67 pacientes com dor miofascial nos músculos mastigatórios e 67 pacientes com dor intra-capsular na ATM segundo o RDC/TMD. Os resultados revelaram um aumento na frequência de doenças psicológicas dentro do grupo de cefaleia crônica diária $(C C D)$ e dor miofascial quando comparados com o grupo de dor intra-capsular e uma qualidade de sono relativamente pior nos pacientes com dor miofascial, que segundo o autor, ocorreu devido à intensidade e duração da dor. Assim, neste trabalho o RDC/TMD foi utilizado para classificar o diagnóstico causal de DTM porém não foram correlacionados de maneira clara os achados do RDC/TMD com achados da cefaleia.

Glaros et al, (2007), avaliaram a presença de DTM em um grupo de 25 pacientes com cefaleia e com um grupo de 17 controles, observaram que uma grande proporção dos pacientes com cefaleia apresentou diagnóstico de DTM do grupo 1, dor miofascial, em relação aos controles sem cefaleia. Os resultados do trabalho são limitados pelo pequeno tamanho da amostra, pela não especificação dos grupos de cefaleia e pela não avaliação da severidade da DTM nos pacientes.

Ballegaard et al., (2008), também demonstraram uma alta freqüência de DTM nos voluntários com cefaleia, cerca de 46,9\% receberam diagnóstico de dor miofascial. Os autores ainda sugerem que dois tipos de cefaleia combinados, migrânea e CTT, pode ser fator de risco para DTM, ou que a DTM pode ser um fator de risco para o desenvolvimento de vários tipos de cefaleia coexistentes.

Porém os resultados destes trabalhos são limitados pelo pequeno tamanho da amostra com variados tipos de cefaléia e pela não avaliação da severidade da DTM nos pacientes.

A determinação da severidade da DTM pode ser realizada por meio do Índice Clínico de Helkimo ou do Índice Anamnésico de Fonseca que é um questionário auto-aplicável (OLIVEIRA, 2003). Este último foi uma tentativa de adaptação para a realidade brasileira do Índice Anamnésico de Helkimo (FONSECA et al., 1994, BEVILAQUA-GROSSI et al., 2006).

Não apenas a frequência DTM, tem sido associada à cefaleia, mas também a sua severidade. Alguns estudos demonstraram que, com o aumento da severidade da DTM maior a frequência de cefaleia e o tratamento da DTM resulta na redução dos fatores da cefaleia, como frequência, duração e intensidade (LILJESTRÖM et al, 2001; BEVILAQUA-GROSSI et al., 2006). 
Dos 109 voluntários sadios, avaliados quanto a presença se sinais e sintomas de DTM, por Bevilaqua-Grossi et al., 2006, 63\% tinham queixa de cefaleia frequente e dentro dos voluntários considerados com DTM severa essa porcentagem subiu para $90 \%$.

Similarmente, em estudo populacional conduzido no Brasil, foi demonstrado que a maior severidade da DTM está mais associada à CCD do que à cefaleia do tipo tensional, portanto a severidade de ambas (DTM e migrânea) estão correlacionadas (GONÇALVES; SPECIALI; BIGAL, 2009).

Portanto, pacientes com cefaleia tendem a apresentar maiores graus de severidade da DTM, ou seja, podem apresentar maiores graus de comprometimento, muscular, articular ou misto em relação a pacientes sem cefaleia, tornando importante não apenas o conhecimento do diagnóstico de DTM como também a severidade da mesma. O melhor conhecimento das influências da DTM nos pacientes com cefaléia também poderá contribuir para uma melhor abordagem de tratamento. 


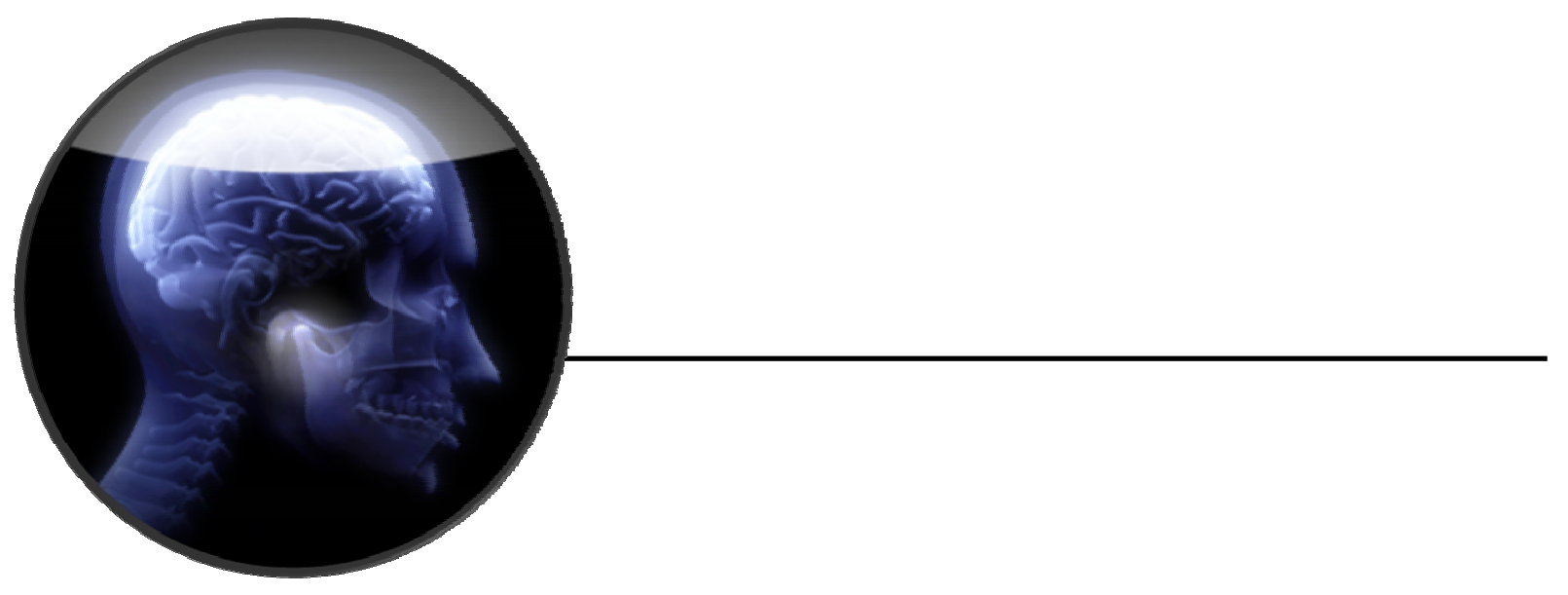

Objetivo

"O coração do homem traça o seu caminho, mas o Senhor lhe dirige os passos. Há caminhos que ao homem parece direito, mas ao cabo dá em caminhos de morte" Provérbios, cap. 16, v.9; cap. 14, v.12. 


\section{OBJETIVO}

O objetivo deste trabalho foi avaliar a frequência da DTM a partir da aplicação do RDC/TMD e a severidade através do Índice Anamnésico de Fonseca em mulheres com Migrânea, Migrânea Crônica e mulheres sem queixa de cefaleia. 


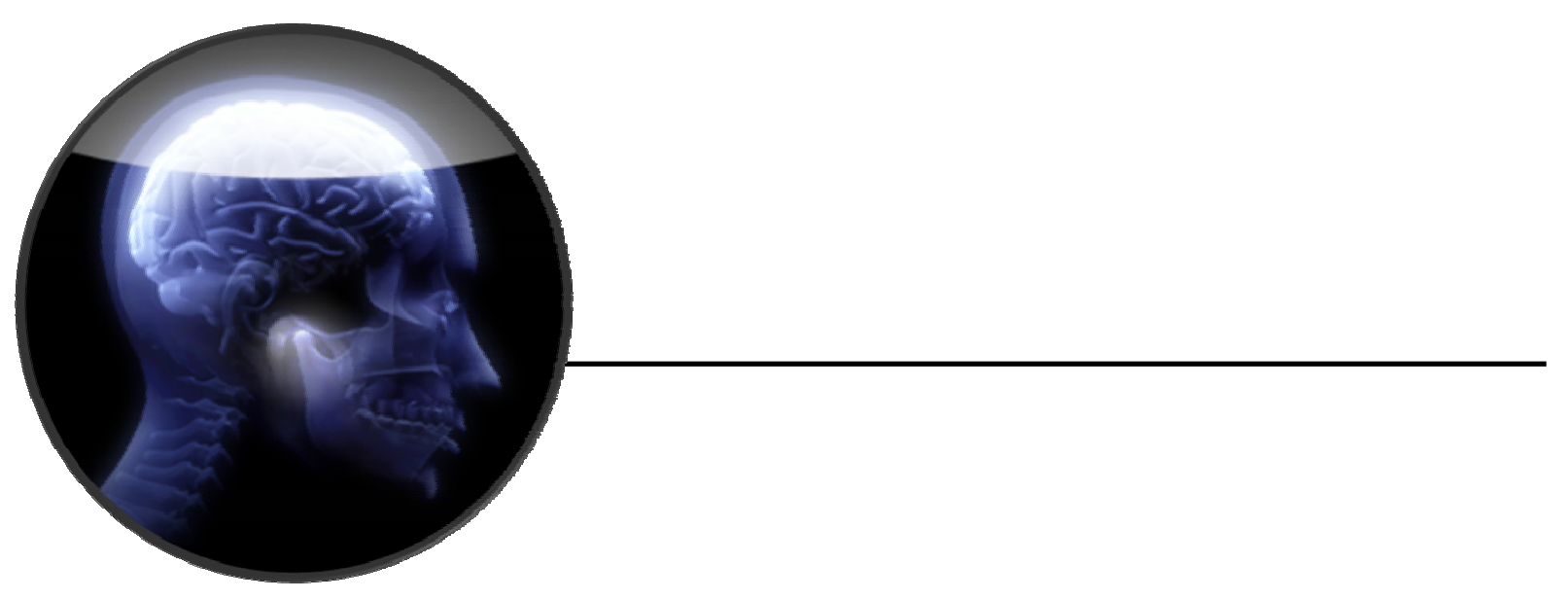

Material e Métodos

"Então, disseram: Disponhamo-nos e edifiquemos. $E$ fortaleceram as mãos para a boa obra. $O$ Deus dos céus é quem nos dará bom êxito; nós, seus servos, nos disporemos e reedificaremos". Neemias Cap. 2, v.18b e20a. 


\section{MATERIAL E MÉTODOS}

\subsection{Amostra}

Participaram deste estudo 91 mulheres, divididas em três grupos: 30 mulheres no Grupo Controle (GC), 38 mulheres no Grupo Migrânea (GM) e 23 mulheres no Grupo Migrânea Crônica (GMC). Não foram observadas diferenças entre as idades das voluntárias (tabela 1). As voluntárias foram selecionadas durante a primeira consulta no Ambulatório de Cefaleia (ACEF) do Hospital das Clínicas de Ribeirão Preto da Faculdade de Medicina da Universidade de São Paulo.

Tabela 1. Valores médios e desvios padrões da idade e frequência em porcentagem do número de indivíduos com diagnóstico de DTM segundo o RDC, das voluntárias dos Grupos Controle (GC), Migrânea (GM) e Migrânea Crônica (GMC), (n=91).

\section{Grupos}

Número de indivíduos com diagnóstico

(\%)
$\mathrm{GC}(\mathrm{n}=30)$
$39,07 \pm 10,04^{*}$
$11(36,66 \%)^{* *}$
$\mathrm{GM}(\mathrm{n}=38)$
$39,16 \pm 9,30$
$33(86,84 \%)$
$\operatorname{GMC}(\mathrm{n}=23)$
$38,83 \pm 9,97$
$21(91,30 \%)$

*Diferença entre as idades ANOVA $(\mathrm{p}<0.05),{ }^{* *}$ Diferença do número de diagnósticos Qui-quadrado ( $\left.\mathrm{p}<0.05\right)$

\subsection{Critérios de inclusão e exclusão}

Participaram desde estudos mulheres com idade entre 18 e 55 anos, que não tivessem ingerido antiinflamatórios e/ou analgésicos nas últimas 24 horas antecedentes à avaliação fisioterapêutica, que não tivesse história de trauma na face, nem usasse prótese dentária parcial ou total. Foram excluídos voluntários com outros tipos de cefaleia e doenças sistêmicas como fibromialgia e artrite reumatóide. As voluntárias selecionadas para o GC, foram submetidas aos mesmos critérios de inclusão e não podiam ter queixa de cefaleia nos últimos 3 meses. Este projeto foi aprovado pelo Comitê de Ética em Pesquisa do Hospital das Clínicas da Faculdade de Medicina de Ribeirão Preto (Anexo A). 


\subsection{Coleta dos Dados}

A coleta dos dados foi dividida em duas etapas e foram utilizados três avaliadores durante as coletas. Os avaliadores I e II fizeram a triagem inicial das mulheres que participaram desde estudo e o avaliador III aplicou as ferramentas utilizadas para a avaliação.

\subsection{Materiais}

Paquímetro analógico (Figura 1) foi utilizado para a mensuração da Amplitude de Movimento da Mandíbula e dois pares de luvas de procedimento foram utilizados para a palpação intra-oral e mensuração da Amplitude de Movimento da Mandíbula.

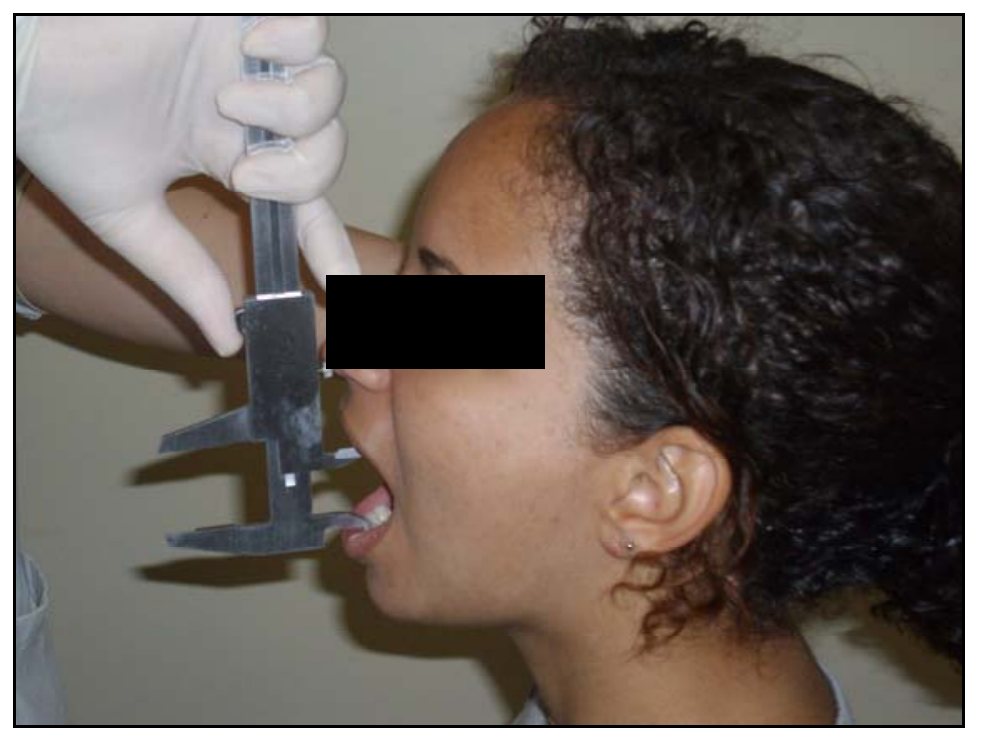

Figura 1. Demonstração da mensuração da amplitude de movimento mandibular utilizando o paquímetro

\subsection{Procedimento}

A primeira etapa foi realizada pelos avaliadores I e II e consistiu: do acompanhamento das consultas das mulheres no ACEF, após a consulta, convite das mulheres com diagnóstico de Migrânea e Migrânea Crônica para participar da pesquisa (as mulheres que aceitavam passavam por uma triagem feita através dos critérios de inclusão e exclusão e pela consulta prévia dos prontuários), seleção e convite das mulheres do GC entre os acompanhantes das pacientes que vinham para consulta no ACEF naquele dia (as mulheres que aceitavam também passavam por uma triagem através dos critérios de inclusão e exclusão), condução 
das voluntárias até a sala de avaliação fisioterapêutica de maneira aleatória, a fim de que o avaliador III não soubesse a qual a voluntária pertencia. O diagnóstico das voluntárias com cefaleia foi feito por neurologistas e totalmente baseado nos critérios da classificação da Sociedade Internacional de Cefaleias (2004).

Na segunda etapa do procedimento, o avaliador III, que era cego para as condições dos voluntários (controle ou pacientes), forneceu informações sobre o procedimento ao quais as voluntárias seriam submetidas e todas assinaram o Termo de Consentimento Livre e Esclarecido (Anexo B). Em seguida foi aplicou o Questionário de Fonseca et al (1994) (Anexo C) adaptado e o RDC/TMD (Anexo D).

\subsubsection{Aplicação do índice Anamnésico de Fonseca}

Na aplicação do Questionário de Fonseca foi a retirada a pergunta número quatro "Sente dores de cabeça com freqüência?", A fim de que o examinador III não soubesse se a voluntária tinha ou não cefaleia. Porém essa informação era adicionada a pontuação posteriormente que poderia ir de 0 a 100. As demais perguntas foram feitas na mesma sequência para todas as voluntárias.

\subsubsection{Aplicação do RDC/TMD}

O RDC/TMD foi aplicado e o diagnóstico das DTMs foram feitos conforme as instruções e na ordem contida no manual (DWORKIN;LERESCHE,1992). As avaliações foram realizadas com as voluntárias na posição sentada, com os joelhos fletidos e mãos amparadas sobre os joelhos. Durante todo o procedimento as voluntárias foram instruídas a manter a musculatura mastigatória relaxada e o examinador aplicou uma resistência manual contralateral à pressão aplicada para assegurar a estabilização da voluntária (GOULET., et al, 1998) (Figura 2). A voluntária comunicava verbalmente a dor sentida, segundo a escalas do RDC/TMD previamente explicada e então a aplicação da pressão era interrompida e o valor era registrado pelo avaliador III. 


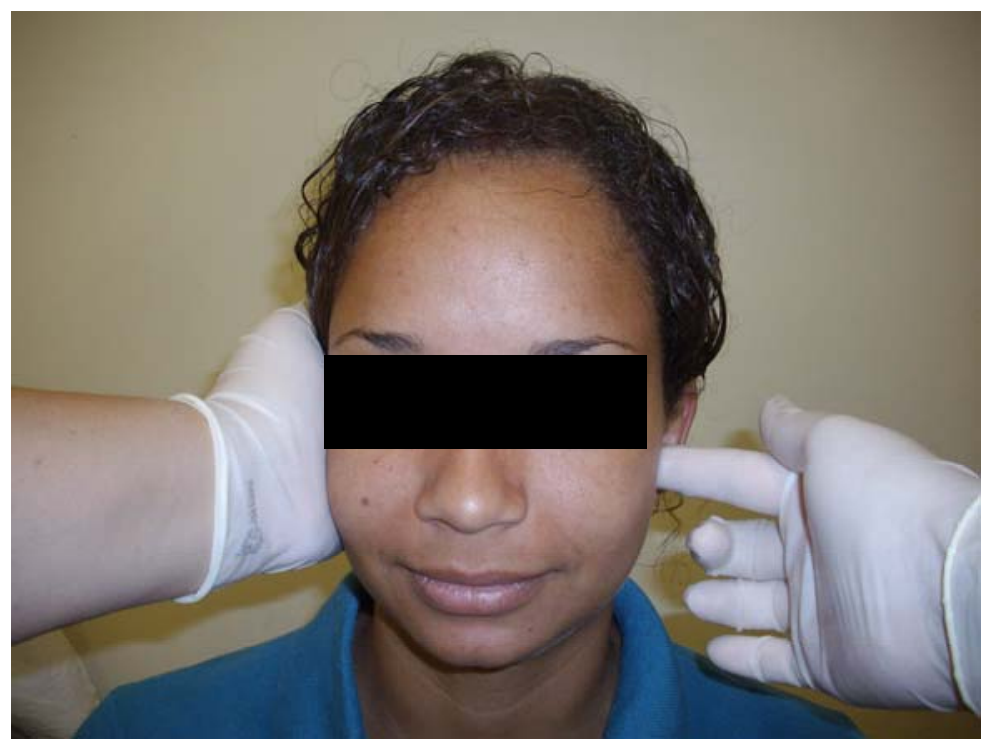

Figura 2. Demonstração da estabilização contra lateral da cabeça do voluntário

Para efetuar a palpação manual, o avaliador III foi previamente treinado por 15 horas. O treinamento foi realizado com o uso de um algômetro e o examinador foi treinado a aplicar pressões no intervalo de 0,5 a $1,0 \mathrm{~kg} / \mathrm{cm}^{2}$ para a palpação das estruturas intra-orais e Articulação Temporomandibular (ATM) e para palpação das demais estruturas foi considerado um intervalo de 1,5 a $2,5 \mathrm{~kg} / \mathrm{cm}^{2}$ (GOULET., et al, 1998).

A palpação manual foi realizada sempre com o uso do dedo indicador direito (polpa da falange distal - (DWORKIN; LERESCHE, 1992) com pressão firme e mantida pontualmente, evitou-se alterações no nível de pressão aplicado. As voluntárias deveriam estar relaxadas com a mandíbula em posição de repouso, sem contato entre os dentes e os músculos também relaxados.

$\mathrm{Na}$ palpação das estruturas intra-orais e intra-auricular foram utilizadas luvas de procedimentos descartáveis. Os seguintes pontos foram palpados bilateralmente de acordo com as orientações do RDC/TMD (DWORKIN; LERESCHE, 1992):

- Músculo Temporal:(fascículo anterior: Ponto mais proeminente e anterior identificado na palpação manual durante máximo apertamento dentário (Figura 3 ), fascículo médio: ponto localizado a uma distância de $3 \mathrm{~cm}$ da região determinada para o fascículo anterior do músculo temporal (Figura 4), e fascículo posterior: Ponto localizado numa distância de $6 \mathrm{~cm}$ da região determinada para o fascículo anterior do músculo temporal (Figura 5); 
- Músculo masseter : Origem : região superior mais proeminente identificada na palpação manual durante máximo apertamento dentário (Figura 6), ventre: ponto médio localizado entre a origem e a inserção ( (Figura 7) (LIST;HELKIMO;FALK,1989), inserção: região inferior mais proeminente identificada na palpação manual durante máximo apertamento dentário (Figura 8);

- Região Posterior da mandibula: (estilo hióide/digástrico posterior) Ponto localizado numa área entre a inserção do músculo esternocleidomastóideo e a borda posterior da mandíbula (Figura 9);

- Região sub mandibular (Pterigóideo medial, supra hióide, digástrico anterior):

Ponto localizado abaixo da mandíbula $2 \mathrm{~cm}$ anterior ao ângulo da mandíbula (Figura 10);

- Polo lateral da ATM: o dedo indicador foi posicionado a frente do tragus da orelha e sobre a ATM, pedindo se para o voluntário abrir levemente a boca, enquanto o examinador tentava encontrar o pólo lateral do côndilo se movimentando para frente (Figura 11);

- Polo posterior da ATM: ponto localizado na área dentro do meato acústico, as pontas dos dedos foram posicionadas na direção do examinador e o voluntário foi solicitado a abrir levemente a boca para que o movimento articular fosse percebido com a ponta do dedo. A pressão foi aplicada quando os dentes do voluntário estavam em oclusão (Figura 12);

- Area do pterigóide lateral: ao voluntário foi solicitado que abrisse a boca e movimentasse a mandíbula para o lado que estava sendo examinado. ("Movimente a sua mandíbula para o lado desta mão"). O dedo indicador foi posicionado na lateral acima do topo alveolar do maxilar posterior aos molares e movimentando distalmente, para cima, e medialmente (Figura 13);

- Tendão do temporal: logo após a palpação da área do músculo pterigóide lateral, o dedo indicador foi rotacionado lateralmente próximo ao processo coronóide, e o voluntário foi convidado a abrir a boca levemente e o dedo indicador foi movimentando para cima em direção ao topo do processo coronóide. 


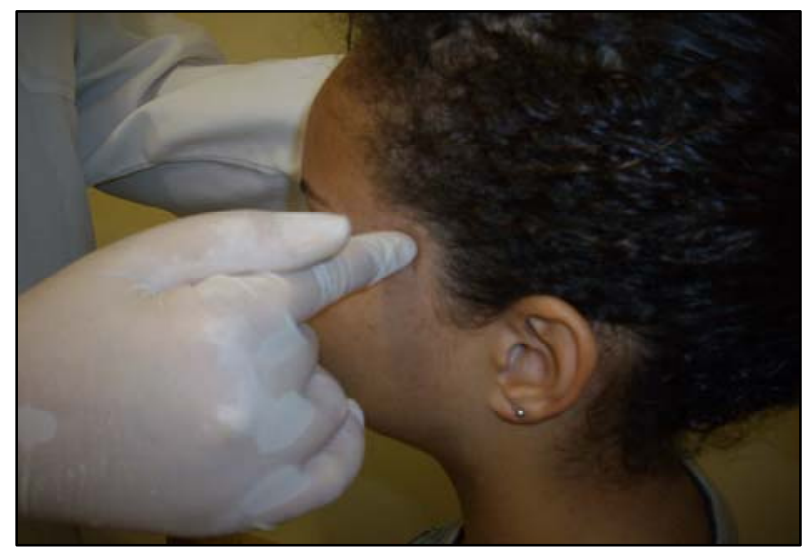

Figura 3. Palpação manual do fascículo anterior do músculo temporal.

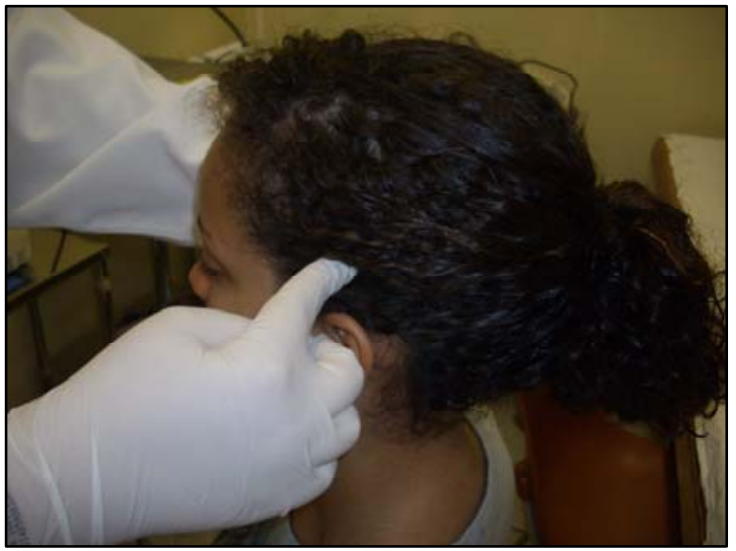

Figura 5. Palpação manual do fascículo posterior do músculo temporal.

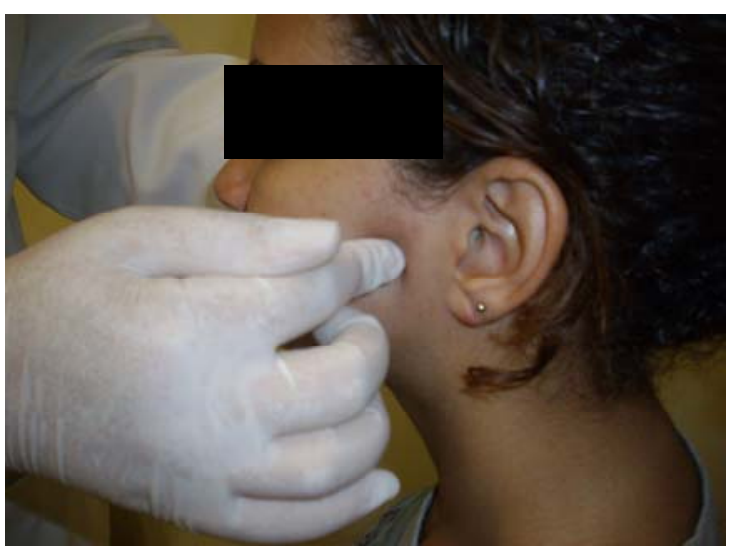

Figura 7. Palpação manual do ventre do músculo Masseter.

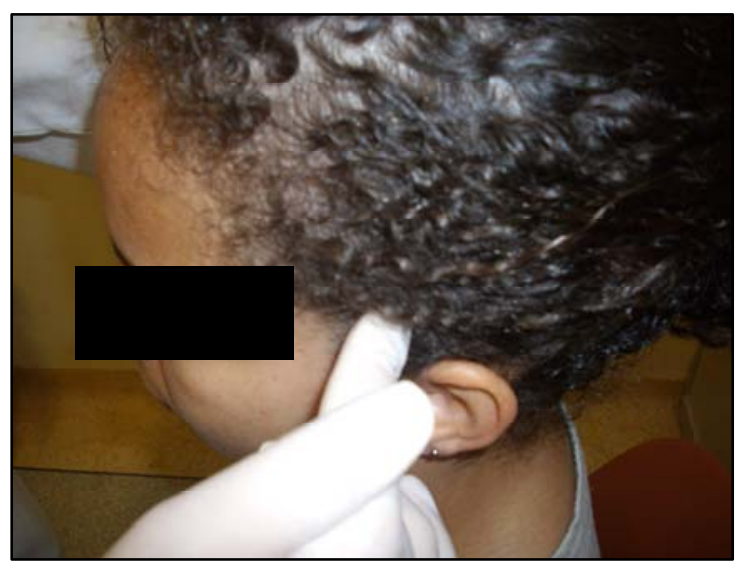

Figura 4. Palpação manual do fascículo médio do músculo temporal.

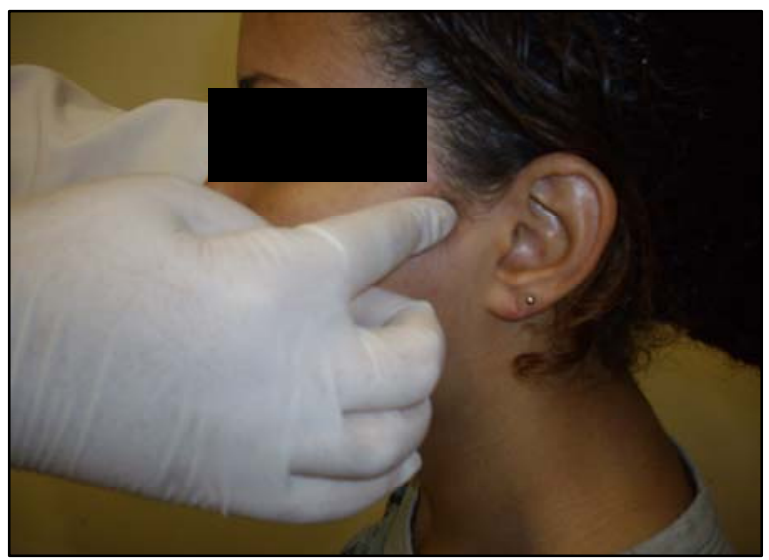

Figura 6. Palpação manual da origem do músculo masseter.

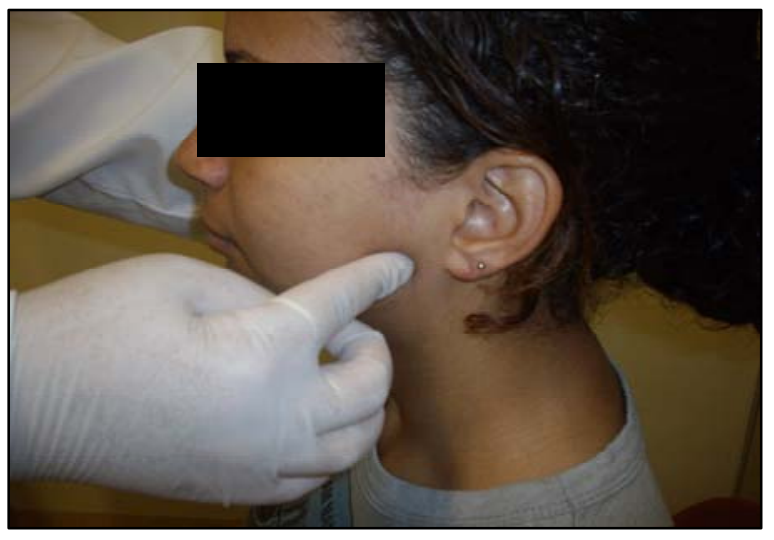

Figura 8. Palpação manual da inserção do músculo masseter. 


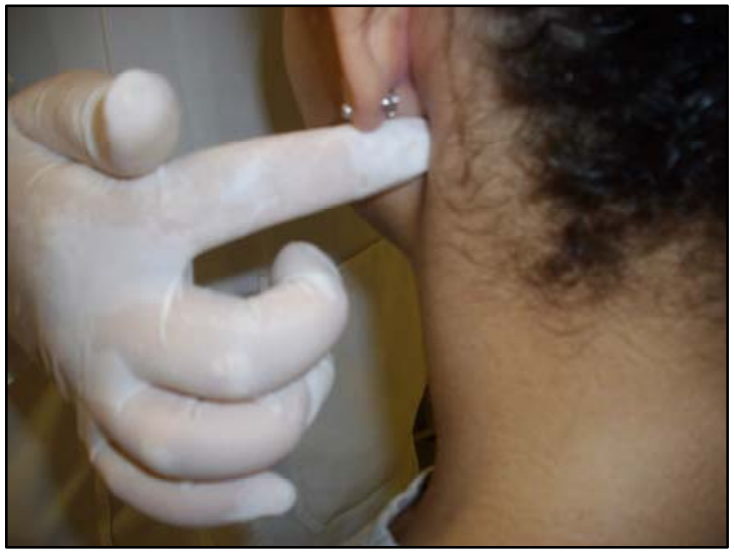

Figura 9. Palpação manual da região posterior da mandíbula.

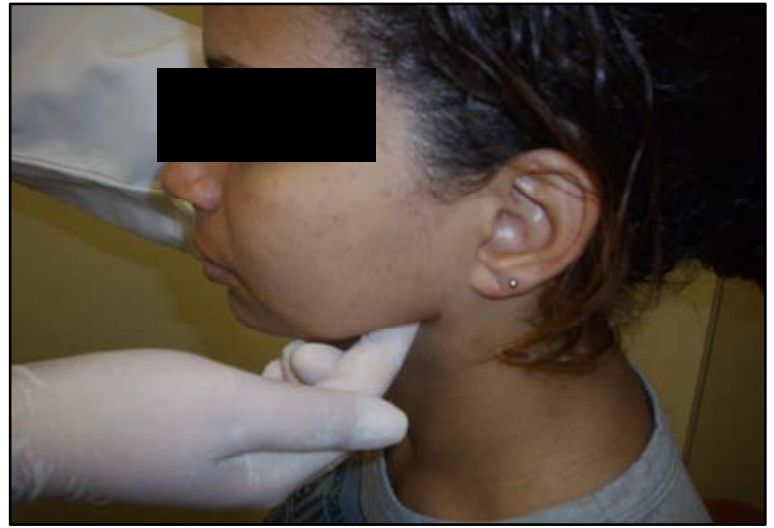

Figura 10. Palpação manual da região submandibular (músculo pterigóide medial).

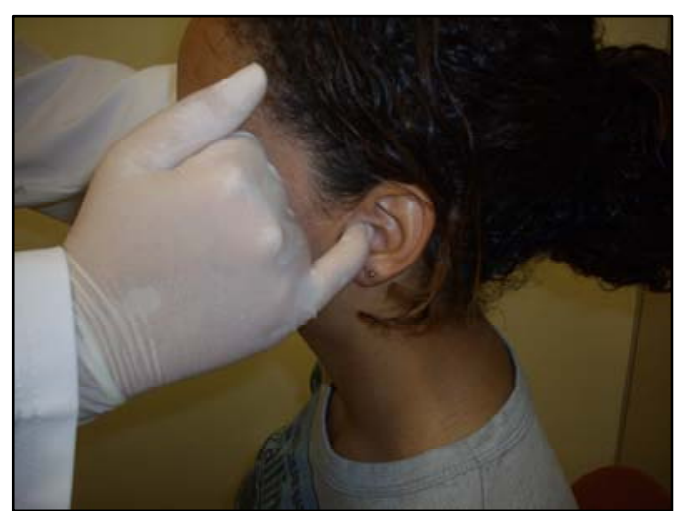

Figura 12. Palpação manual do pólo posterior da ATM

Figura 11. Palpação manual do pólo lateral da ATM.

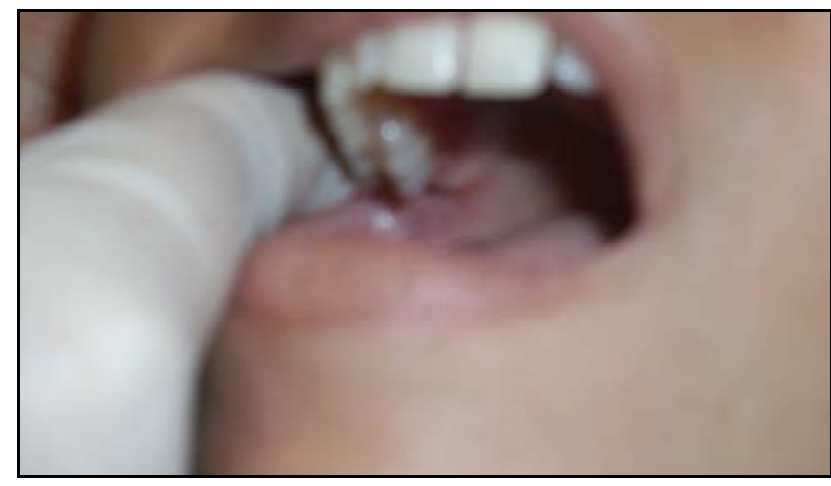

Figura 13. Palpação intra oral da cabeça lateral do músculo pterigóide lateral 


\subsection{Análise dos dados}

Para comparação dos dados antropométricos e da amplitude de movimento mandibular entre os três grupos (Controle, Migrânea e Migrânea Crônica) foi empregada a análise da variância (ANOVA two-Way p<0.05) e Tukey como análise post-hoc para avaliar a diferença no número de locais dolorosos e o número de diagnósticos, com nível de significância de $\mathrm{p}<0,05$.

O teste qui-quadrado foi utilizado para verificar a diferença nas porcentagens de diagnóstico entre os três grupos.

Para verificar freqüência da severidade entre os três grupos foi utilizado o empregado o teste exato de Fisher. 


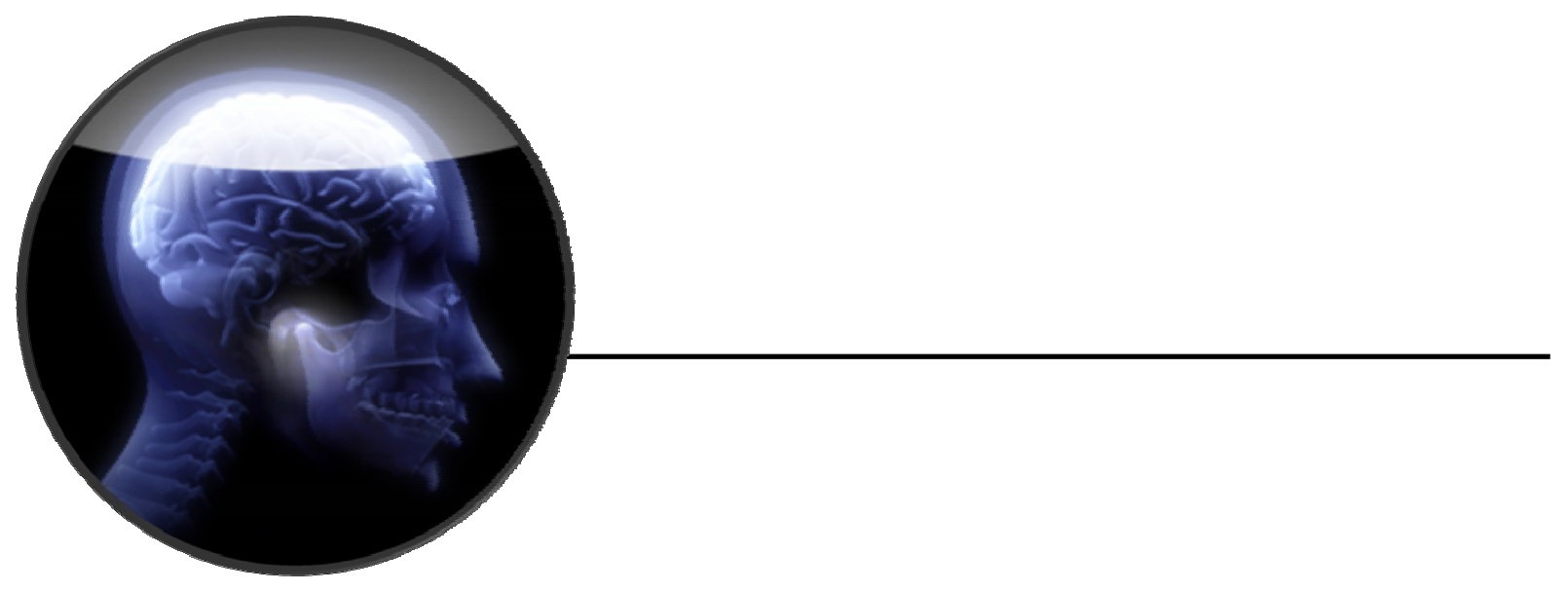

Resultados

"Confia no Senhor de todo o teu coração e não te estribes no teu próprio entendimento. Reconhece-o em todos os teus caminhos, e ele endireitará as tuas veredas". Provérbios Cap. 3, v.5-6. 


\section{RESULTADOS}

As voluntárias dos grupos com migrânea apresentaram maior freqüência de diagnósticos de Disfunção Temporomandibular (DTM) (Tabela 1) e maiores graus de severidade de DTM, em comparação ao GC, p<0,05 (Tabela 2).

Tabela 1. Valores médios e desvios padrões da idade e frequência em porcentagem do número de indivíduos com diagnóstico de DTM segundo o RDC, das voluntárias dos Grupos Controle (GC), Migrânea (GM) e Migrânea Crônica (GMC), (n=91).

Grupos Idade (anos) Número de indivíduos com diagnóstico
$\mathrm{GC}(\mathrm{n}=30)$
$39,07 \pm 10,04^{*}$
$11(36,66 \%)^{* *}$
GM $(n=38)$
$39,16 \pm 9,30$
$33(86,84 \%)$
$\operatorname{GMC}(\mathrm{n}=23)$
$38,83 \pm 9,97$
$21(91,30 \%)$

*Diferença entre as idades ANOVA ( $\mathrm{p}<0.05),{ }^{* *}$ Diferença do número de diagnósticos Qui-quadrado $(\mathrm{p}<0.05$

Tabela 2. Freqüência da severidade da Disfunção Temporomandibular entre os grupos Controle (GC), Migrânea (GM) e Migrânea Crônica (GMC) n=91.
Grupos
Severidade

Sem DTM DTM Leve DTM Moderada DTM Severa

$\mathrm{GC}(\mathrm{n}=30) \quad 10(33 \%)^{*} \quad 14(47 \%)^{*} \quad 5(17 \%) \quad 1(3,33 \%)$

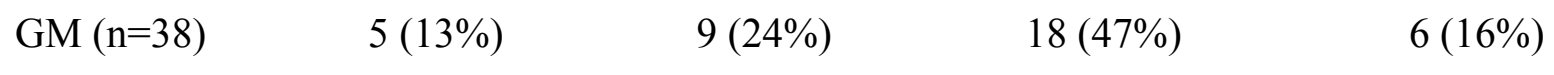

$\operatorname{GMC}(n=23)$

$0(0 \%)$

$6(26 \%)$

$9(39 \%)$

$8(35 \%)^{* *}$

*Diferença em relação aos grupos com migrânea, ** Diferença em relação ao grupo controle e Migrânea. Teste exato de Fisher. 
Os diagnósticos do grupo I foram os mais prevalentes nos três grupos estudados. Os diagnósticos mistos dos grupos I+II e I+II+III foram encontrados somente nos grupos com migrânea, com maior freqüência no grupo GMC. Os diagnósticos dos grupos I+III estiveram presentes nos três grupos estudados e foi constatada maior freqüência no grupo GM em relação aos demais grupos. Não foram encontrados diagnósticos individuais pertencentes apenas aos grupos II e III (tabela 3).

Tabela 3. Freqüência em porcentagem de indivíduos com diagnóstico de DTM simples e mistos das voluntárias dos grupos Controle (GC), Migrânea (GM) e Migrânea Crônica (GMC), (n=91).

\section{Grupos}

GC $(n=30)$

GM (n=38)

GMC (n=23)

\section{Grupo I}

$$
9(29,99 \%) * \quad 21(55,88 \%)
$$

Grupo I+II

0

$4(10,52 \%)$

$2(8,70 \%)$

\section{Grupo I+III}

$$
1(3,33 \%) \quad 8(20,64 \%)^{* *}
$$

\section{Grupo I+II+III}

$0 \quad 1(2,63 \%)$

$4(17,34 \%)^{* * *}$

*Diferença em relação aos grupos com Migrânea, **Diferença em relação aos grupos controle e Migrânea Crônica ***Diferença em relação aos grupos controle e Migrânea. Qui-quadrado ( $<<0.05)$, I-Dor miofascial, II- Deslocamento de disco, III-artrite

Foi observado número significativamente maior de diagnósticos de DTM no GM e GMC em relação ao controle $\mathrm{p}<0,05$, porém não foi observada diferença entre os grupos GM e GMC p $>0,05$. O número de pontos dolorosos musculares, máximo de 20 pontos, foi significativamente maior nos grupos GM e GMC em relação ao controle e não houve diferença entre os grupos com Migrânea. Não houve diferença entre os grupos quanto ao número de pontos dolorosos articulares, máximo de 4 pontos, (tabela 4 ). 
Tabela 4. Médias e Desvios Padrões do número de diagnóstico de acordo com o RDC, número de pontos dolorosos musculares $(\mathrm{n}=20)$ e número de pontos dolorosos articulares $(n=4)$.

\begin{tabular}{lccc}
\hline Grupos & $\begin{array}{c}\mathbf{N}^{\mathbf{0}} \text { Diagnósticos } \\
\mathbf{R D C}\end{array}$ & $\begin{array}{c}\mathbf{N}^{\mathbf{0}} \text { Pontos } \\
\text { dolorosos } \\
\text { musculares }(\mathbf{n}=\mathbf{2 0})\end{array}$ & $\begin{array}{c}\mathbf{N}^{\mathbf{0}} \text { Pontos } \\
\text { dolorosos articulares } \\
(\mathbf{n}=\mathbf{4})\end{array}$ \\
\hline GC $(\mathrm{n}=30)$ & $0,45 \pm 0,72^{*}$ & $7,03 \pm 5,52^{*}$ & $0,63 \pm 0,96$ \\
$\mathrm{GM}(\mathrm{n}=38)$ & $1,47 \pm 1,05$ & $14,73 \pm 5,75$ & $1,78 \pm 1,41$ \\
GMC $(\mathrm{n}=23)$ & $1,87 \pm 1,15$ & $16,21 \pm 3,89$ & $1,78 \pm 1,16$ \\
\hline * Diferença em relação aos grupos com migrânea, ANOVA two-Way $(p<0.05)$ &
\end{tabular}

* Diferença em relação aos grupos com migrânea, ANOVA two-Way $(p<0.05)$

Não houve diferença entre os grupos quanto a amplitude de movimento mandibular, para os movimentos, máxima abertura da boca (MAB), máxima abertura da boca ativa (MABA) e máxima abertura da boca passiva (MABP), exceto quando foram comparados os grupos migrânea e controle, houve diferença na MAB, $p<0,01$, (tabela 4).

Tabela 5. Valores médios e desvios padrões da amplitude de movimento mandibular dos voluntários dos grupos Controle (GC), Migrânea (GM) e Migrânea Crônica (GMC), (n=91).
Grupos
Movimentos

$\begin{array}{cccc} & \text { MAB } & \text { MABA } & \text { MABP } \\ \text { Controle }(\mathrm{n}=30) & 46,77 \pm 7,66^{*} & 52,21 \pm 7,01 & 51,20 \pm 7,24 \\ \text { Migrânea }(\mathrm{n}=38) & 42,08 \pm 7,63 & 49,79 \pm 6,30 & 48,37 \pm 7,16 \\ \text { grânea Crônica }(\mathrm{n}=23) & 43,52 \pm 3,76 & 49,74 \pm 5,71 & 49,43 \pm 5,65\end{array}$

*Diferença em relação aos grupos com migrânea. 


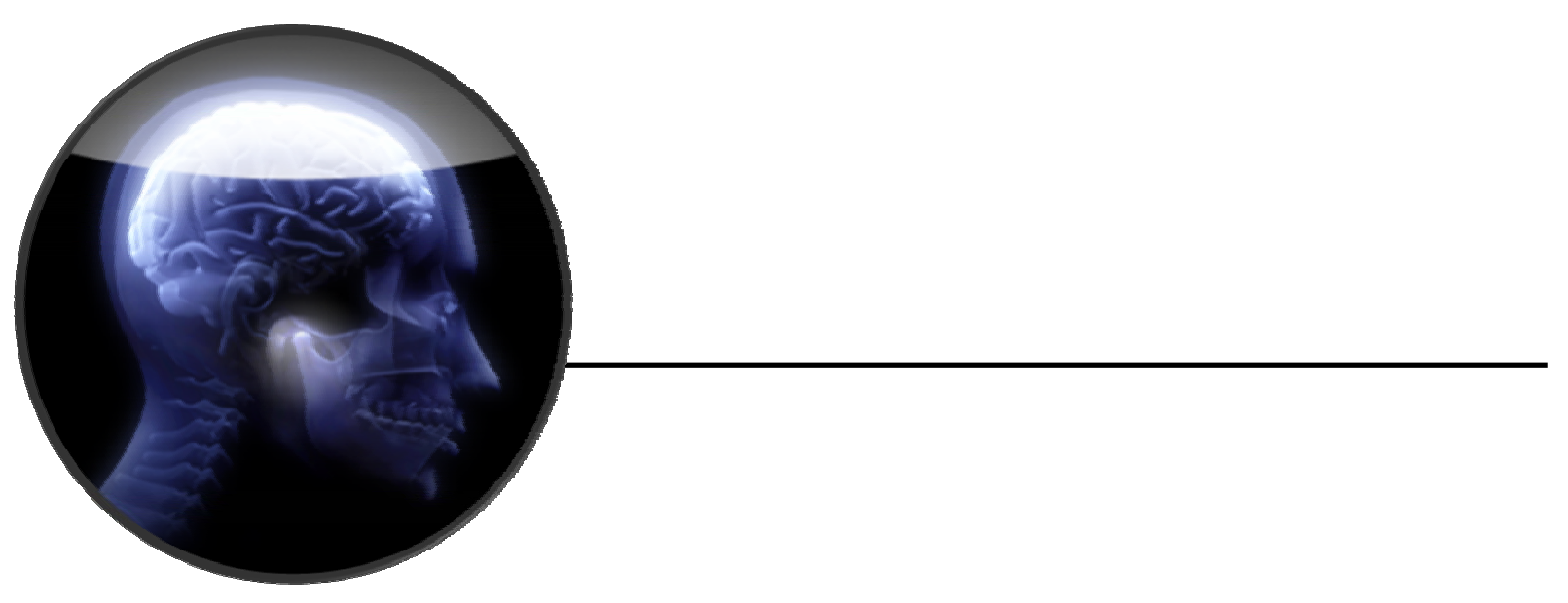

Discussão

"Mas Deus escolheu as coisas loucas desse mundo para confundir as sábias; e Deus escolheu as coisas fracas deste mundo para confundir as fortes; e Deus escolheu as coisas humildes deste mundo e as desprezadas, e as que não são, para reduzir a nadar as que são" $1^{\circ}$ Coríntios, cap. 1, v.27-28. 


\section{DISCUSSÃO}

Inicialmente serão discutidas a homogeneidade da amostra e a diferença significativa da frequência de DTM entre os grupos com e sem cefaleia.

$\mathrm{Na}$ seqüência serão discutidos os diagnósticos e os graus de severidade de DTM encontrados, a frequência dos diagnósticos, a diferença no número de diagnósticos e os pontos dolorosos entre os três grupos. E finalmente serão destacadas as diferenças entre os grupos quanto a amplitude de movimento mandibular.

Não foram observadas diferenças entre a idade dos três grupos estudados. A maioria das voluntárias estava na faixa etária de 39 anos.

Os achados desta pesquisa são semelhantes com os de Glaros., et al, (2007) e Ballegaard., et al, (2008) que encontraram voluntários com média de idade entre 38 e 44 anos, confirmando que a Migrânea tem seu pico de maior prevalência entre as idades de 25 e 55 anos (BIGAL., et al, 2000) e a DTM tem seu pico de maior prevalência entre as idades de 35 e 45 anos (LERESCHE, 1997) e acometem os indivíduos nas fases mais produtivas da vida.

As voluntárias com Migrânea apresentaram maior freqüência de DTM que as voluntárias do GC. Das voluntárias do GC, apenas 37\% das voluntárias apresentaram algum diagnóstico de DTM em relação ao GM (87\%) e GMC (91\%). Porém essa maior freqüência não altera quando são comparados os grupos de migrânea entre si.

Estudos clínicos que utilizaram o RDC/TMD também relataram uma proporção significativamente maior de diagnósticos de DTM em voluntários com cefaleia quando comparados aos sem cefaleia (GLAROS;URBAN;LOCKE, 2007, BALLEGAARD., et al, 2008).

Da mesma forma estudos que avaliaram a DTM por meio de sinais e sintomas também encontraram maior frequência de DTM em pacientes com cefaleia (SCHOKKER., et al, 1990, CIANCANGLINI; RADAELE, 2001).

O diagnóstico de dor miofascial foi o mais freqüente entre os três grupos e apresentou diferença significativa para os grupos GM e GMC em relação ao controle $(p<0,05)$. As mulheres com migrânea e migrânea crônica apresentaram freqüência significativamente maior de diagnósticos do grupo muscular (grupo I) em relação aos diagnósticos de deslocamentos de disco (grupo II) e artralgia, osteoartrite e osteoartroses (grupo III).

Não foram observados mulheres com diagnósticos somente do grupo II e III, e os diagnósticos mistos (I+II, I+III e I+II+III) apesar de presentes nos três grupos apresentaramse mais frequentes nas mulheres com migrânea. Outros autores também demonstraram que os 
diagnósticos dos grupos II e III são encontrados com maior frequência em conjunto com os diagnósticos do grupo I. (BALLEGAARD., et al, 2008).

Semelhantemente, maior sensibilidade dolorosa da musculatura mastigatória, também tem sido encontrada quando avaliada a DTM por meio de sinais e sintomas. No estudo conduzido por Stuginski-Barbosa., et al, 2010, realizado em um hospital terciário, o sintoma de dor muscular estava significativamente mais presente nos grupos com migrânea em relação ao grupo controle.

A presença da dor miofascial em um paciente com migrânea, pode agravar o sintoma de cefaleia uma vez que duas condições dolorosas estão presentes no mesmo individuo. A presença de frequente de dor muscular produz um continuo impulso nociceptivo para o sistema trigeminal, aumentando o limiar para os ataques de migrânea (FERNÁNDEZ-DELAS-PEÑAS; CUADRADO e PAREJA, 2006). A influência mútua exercida entre essas duas condições, indica o compartilhamento de mecanismos fisiopatológicos comuns, ou mesmo, compartilham mecanismos etiológicos similares (GLAROS., et al, 2007) e/ou fatores contribuintes (STORM;WANMAN, 2006).

Segundo o RDC/TMD cada individuo pode receber até cinco diagnósticos, sendo um muscular e dois articulares para cada articulação. Na comparação entre os grupos foi observado que dos cinco diagnósticos que cada voluntária poderia receber, no GC pode-se afirmar que as voluntárias receberam "menos que um diagnóstico" uma vez que cada voluntária recebeu em média 0,45 diagnósticos de DTM. Já nos GM e GMC, cada uma das voluntárias, recebeu em média 1,47 e 1,87 diagnósticos de DTM respectivamente, quase três vezes mais diagnósticos que o $\mathrm{GC}$, todavia entre os $\mathrm{GM}$ e $\mathrm{GMC}$ não houve diferença estatística quanto aos números de diagnósticos.

Portanto, além de apresentarem maior freqüência do diagnóstico de DTM, as voluntárias dos grupos com migrânea também receberam maior número de diagnósticos de DTM em relação às voluntárias do $\mathrm{GC}$, isto é, o individuo com migrânea não apenas apresenta maior frequência de diagnósticos como também apresenta um maior comprometimento da disfunção, revelando que as mulheres com migrânea são acometidas por diagnósticos mais complexos, envolvendo estruturas musculares e articulares, em relação às mulheres sem migrânea.

Os dados deste trabalho indicam que as mulheres com migrânea tendem a ter mais de um diagnóstico de DTM, sugerindo que ter migrânea pode ser um fator de influencia negativa no diagnóstico de DTM, agravando ainda mais um condição já existente. 
Algumas hipóteses podem ser sugeridas para esta associação entre a Migrânea e DTM. Mecanismos de sensibilização central e periférica, envolvidos na percepção dolorosa presentes na migrânea (SARLANI, et al; 2005), podem difundir dor para a região craniocervical (JOHN, et al; 2005) levando a sensibilização de regiões da face, portanto os pacientes seriam portadores apenas de migrânea e não DTM. Ou então os mecanismos de sensibilização central contribuiriam para a fisiopatologia e o desencadeamento de ambas Migrânea e a DTM e ainda; a DTM e a migrânea podem ser agravadas ou perpetuadas uma pelos fatores da outra, o paciente com migrânea pode ter sua condição dolorosa agravada ou mesmo estimulada pela coexistência com a DTM ou vice-versa (GRAFF-RADFORD, 2007, FERNÁNDEZ-DE-LAS-PEÑAS; CUADRADO e PAREJA, 2006).

As mulheres com migrânea relataram significativamente mais pontos dolorosos musculares que as mulheres do grupo controle $(p<0,05)$. A maior sensibilidade muscular nas mulheres com migrânea também foi encontrada por outros autores (GLAROS;URBAN e LOCKE, 2007, BEVILAQUA-GROSSI., et al, 2009a), indicando que a cefaleia esta relacionada a problemas músculo-esqueléticos como mialgia e dor miofascial.

Não foram observadas diferenças entre os grupos MC e GC e GMC e GM quanto a amplitude de movimento mandibular, para os movimentos, máxima abertura da boca (MAB), máxima abertura da boca ativa (MABA) e máxima abertura da boca passiva (MABP), porém quando foram comparados o GC e GM, o GM apresentou menores valores para MAB.

Autores sugerem que desvios anormais da função mandibular podem produzir estímulos mecânicos que provocam mudanças na atividade estomatognática, prolongando a estimulação nociceptiva dos músculos mastigatórios, conduzindo assim a uma sensibilização nos nociceptores das regiões cranianas e pericranianas, podendo ser a fonte primária da cefaleia (CIANCAGLINI e RADAELLI, 2001).

Nas bases consultadas, foram encontrados poucos trabalhos que tivessem verificado a severidade da DTM, em mulheres com cefaleia utilizando o Questionário de Fonseca. Neste trabalho a severidade da DTM também foi avaliada e observou-se que as voluntárias com cefaleia tiveram maior severidade da DTM em relação ao GC e que o GMC foi significativamente diferente do GM sugerindo que quanto maior a freqüência da cefaleia maior a severidade da DTM.

A maior severidade da DTM, também foi encontrada estudantes adultos. Do total de indivíduos avaliados por Bevilaqua-Grossi et al., 2006, 63\% tinham queixa de cefaleia freqüente. Quando analisados somente os voluntários com DTM considerada severa, a porcentagem de indivíduos com queixa de cefaleia frequente era de 90\%. Mesmo em 
adolescentes, de ambos os sexos, a severidade dos sinais e sintomas de DTM esta relacionada a maior frequência de migrânea (LILJESTRÖM et al., 2001).

Sugerindo que a severidade da DTM pode estar diretamente relacionada com a frequência ou cronicidade da cefaleia, ressaltando a importância da avaliação do sistema estomatognático nesses pacientes, em especial nos pacientes com migrânea crônica.

Ainda, em estudo populacional, conduzido no Brasil, que avaliou a prevalência da cefaleias em portadores de DTM, demonstrou que a maior severidade da DTM esta mais associada a CCD do que a cefaleia do tipo tensional sugerindo que a severidade de ambas, DTM e migrânea são correlacionadas (GONÇALVES; SPECIALI; BIGAL, 2009).

Assim não apenas a frequência da DTM, mas também a sua severidade esta relacionada com a migrânea, reforçando a idéia de que esses pacientes estão sujeitos a diagnósticos de DTM mais complexos e severos além de poderem apresentar piora dos fatores da migrânea, como freqüência, duração e intensidade, pela sobreposição de sintomas e pela constante presença de dor. 


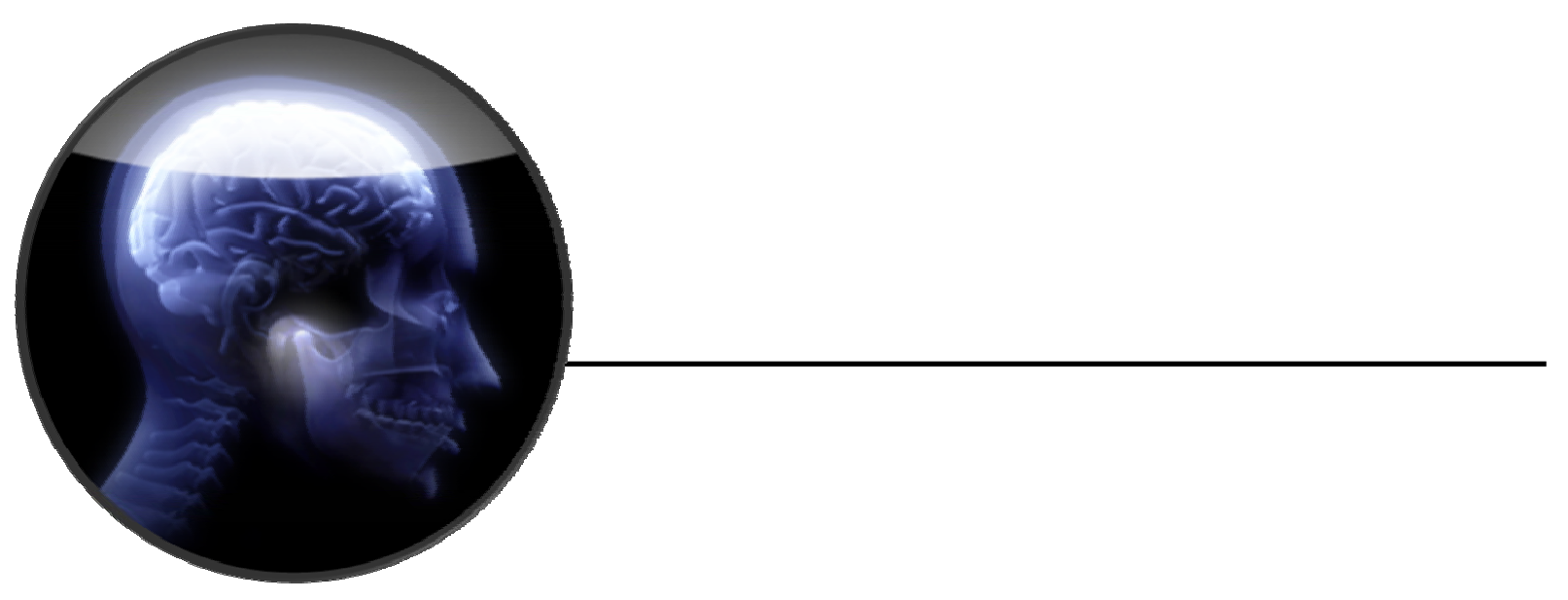

Conclusões

"Buscai primeiro o reino de Deus e a sua justiça e as demais coisas li serão acrescentada. Portanto, não vos enquisteis com o dia de amanhã, pois o amanhã trará os seus cuidados, basta ao dia o seu próprio mal". Mateus, cap. 6, v. 33-34. 


\section{CONCLUSÕES}

A partir dos resultados deste estudo é possível fazer as seguintes considerações;

- A DTM e a Migrânea estão clinicamente relacionadas. Mulheres com Migrânea tem maior frequência e maior comprometimento da DTM, apresentam maior número de diagnósticos e de pontos dolorosos segundo o RDC/TMD que mulheres sem migrânea;

- Mulheres com Migrânea desenvolvem DTM com maior severidade que mulheres sem migrânea, sugerindo que quanto mais severa a Migrânea mais severa a DTM. 


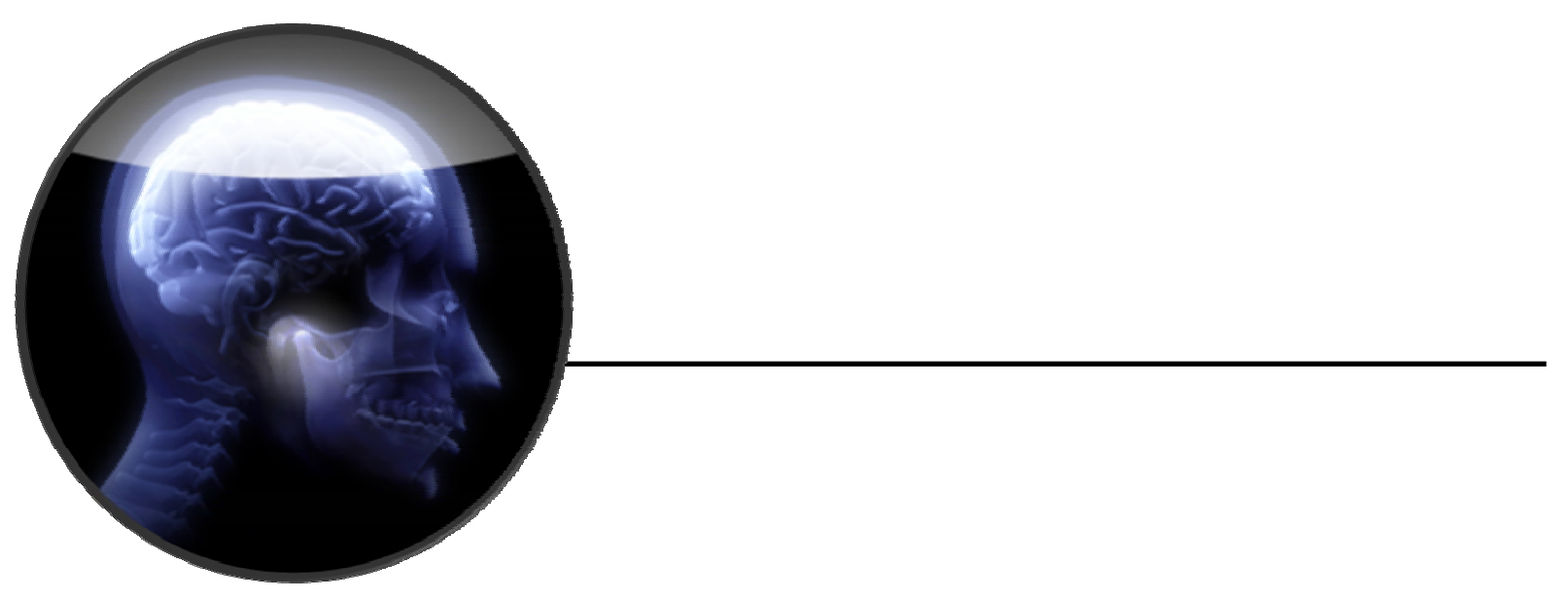

Referencias Bibliográficas

"Não andeis ansiosos de coisa alguma; em tudo, porém sejam conhecidas, diante de Deus, as vossas petições, pela oração e pela súplica, com ações de graça. E a paz de Deus, que excede todo entendimento, guardara o vosso coração e a vossa mente em Cristo jesus".

Filipenses, cap. 4, v. 6-7. 


\section{REFERÊNCIAS BIBLIOGRÁFICAS ${ }^{1}$}

AMERICAN SOCIETY OF TEMPOROMANDIBULAR JOINT SURGEONS (ASTJS). Guidelines for diagnosis and management of disorders involving the temporomandibular joint and related musculoskeletal structures. Cranio, v.21, p.68-76, 2003.

BALLEGAARD, V.; THEDE-SCHMIDT-HANSEN, P.; SVENSSON P, JENSEN R. Are headache and temporomandibular disorders related? A blinded study. Cephalalgia, v.28, p.832-841, 2008.

BAHRA, A.; WALSH, M.; MENOM, S.; GOADSBY, P.J. Does chronic daily headache arise in association with regular use of analgesic? Headache, v.43, p. 170-190, 2003.

BEVILAQUA-GROSSI D. ; LIPTON RB. ; BIGAL EM. Temporomandibular Disorders and Migraine Chronification. Currente Pain \& Headache Reports 2009 ;13 (a) \{in press].

BEVILAQUA-GROSSI D.; CHAVES, T.C.; OLIVEIRA, A.S.; MONTEIRO-PEDRO, V. Anamnestic index severity and signs and symptoms of temporomandibular disorders (TMD). Cranio, v.24, n.2, p.112-118, 2006.

BIGAL, M.E.; FERNANDES, L.C.;MORAES, F.;BORDINE, C.A.; SPECIALI, J.G. Prevalência da migrãnea e impacto sobre a qualidade de vida em funcionários do hospital da clinicas da Faculdade de Medicina de Ribeirão Preto-USP. Arq Neuropsiquiatr., v.58,p.431436, 2000.

BORDINI, C. A. Impacto na vida diária causado pela enxaqueca. In: Congresso Internacional da Sociedade Brasileira de Cefaleia, 12. Anais...1998.

CASTILHO, J.; MUMOZ, D.A.; GUITERA, V.; PASCUAL, J. Epidemiology of chronic daily headache in the general population. Headache v. 39, p. 190-196, 1999.

CIANCAGLINI, R.; RADAELLI, G. The relationship betwwenn headache and symptoms of temporomandibular disorder in the population. Journal of Dentistry v. 29, p.93-98, 2001.

CHAVES, T.C.; OLIVEIRA, A.S.; BEVILAQUA-GROSSI, D. Principais instrumentos para avaliação da disfunção temporomandibular (parte II): critérios diagnósticos; uma contribuição para a pratica clínica e de pesquisa. Fisioterapia e pesquisa, v.15, n.1, p.101-106,2008.

\footnotetext{
${ }^{1}$ De acordo com a Associação Brasileira de Normas Técnicas, 2002b. NBR 10520
} 
CLASSIFICAÇÃO DAS CEFALEIAS DA SOCIEDADE INTERNACIONAL DE CEFALEIAS. Classificação International das cefaleias. Segunda Edição. Trad. Sociedade Brasileira de Cefaleias. São: Segmento Farma Editores, p36-73, 2004.

CUTRER, F. New information in our evolving understanding of migraine aura and cortical spreading depression. Cephalalgia, v.2 9, n.10, p. 1129-1131, 2009.

DWORKIN, S.F; HUGGINS, K. H.; LERESCHE, L.; VON KORF, M.; HOWARD, J.; TRUELOVE, E.L.; SOMMERS, E. Epidemiology of signs and symptoms in temporomandibular disorders: clinical signs in cases and controls. JADA, v.120, p.273281,1990 .

DWORKIN, S.F.; LERESCHE, L. Research diagnostic criteria for temporomandibular disorders: review, criteria, examinatios and specificatios, critique. Journal of craniomandibular disorders : facial \& oral pain. v. 6, p. 301-305, 1992.

FARIAS DA SILVA, W. Algias craniofaciais. São apulo: Lemos Editorial, 1998.

FERNÁNDEZ-DE-LAS-PENÃS, C.; CUADRADO, M.L.; PAREJA, J.A. Myofascial trigger points, neck mobility and forward head posture in unilateral migraine. Cephalalgia. v. 26, p.1061-1070,2006.

FONSECA, D.M.; BONFATE, G.; VALLE, A.L.; FREITAS, S.F.T. Diagnóstico pela anamnese da disfunção craniomandibular. Revista Gaucha de Odontologia., v.42, p.23-28, 1994.

FRICTON, J. Recent advances in temporomandibular disorders and orofacial. JADA, V. 122, P.24-33, 1991.

GLAROS, A.G.; URBAN, D.; LOCKE, J. Headache and temporomandibular disorders: evidence for diagnostic and behavioural overlap. Cephalalgia, v. 27, p.542-549, 2007.

GOADSBY, P.; EDVINSSON, L. The trigeminovascular system and migraine: studies characterizing cerebrovascular and neuropeptide changes in man and cat. Ann neurol v. 33, p. 48-56, 1993.

GOULET, J.P.; CLARK, G.T.; FLACK, V.F. The reproducibility of muscle and joint tenderness detection methds and maximum mandibular moviment measurement for the temporomandibular system. J. Oralfac. Pain. v. 12, n. 1, p. 17-26,1998.

GONÇALVES, D.A.G.; SPECIALI, J.G.; BIGAL, M.E. Headache and symptoms of Temporomandibular joint dysfunction: an epidemiological study. Headache 2009 (in press) 
GREENE, C.S.; MARBACH, JJ. Epidemiologic studies od mandibular dysfunction. J. prosthet. Dent., v. 49, p. 184-190, 1982.

GRAFF-RADFORD, SB. Temporomandibular disorders and other causes of facial pain. Curr Pain Headache Rep. v. 11, p. 75-81, 2007.

HELKIMO, M. Studies on function and dysfunction of the masticatory system. II Index for anamnestic and clinical dysfunction and occlusal state. Swedish Dental Journal, v.67, p.101121,1974 .

JOHN, M.T.; DWORKIN, S.F.; MANCL, L.A. Reliability of clinical temporomandibular disorders diagnoses. Pain v.118, p.61-69, 2005.

KATSARA, Z; SCHNEEWEISS, S; KURTH, T; et al. Incidence and predictors for chronicity of headache in patients with episodic migraine. Neurology, v. 62, p. 788-790, 2004.

LERESCHE, L. Epidemiology of temporomandibular disorders: implications for the investigation of etiologic factors. Critical reviews in oral biology and medicine v.8, p. 291305,1997 .

LILJESTRÖM, M.R.; LE BELL, Y.; ANTTILA, P.; AROMAA, M.; JÄMSÄ, T.; METSÄHONKALA, L.; HELENIUS, H.; VIANDER, S.; JÄPPILÄ, E.; ALANEN, P.; SILLANPÄÄ, M. Headache children with temporomandibular disorders have several types of pain and other symptoms.Cephalalgia v.11, p. 1054-1060, 2005.

LILJESTRÖM, M.R.; JÄMSÄ, A.; LE BELL, Y.; ALANEN, P.; ANTTILA, P.; METSÄHONKALA, L.; AROMAA, M.; SILLANPÄÄ, N. Signs and symptoms of temporomandibular disorders in children with different types of headache. Acta Odontol Scand. v. 59, p. 413-417, 2001.

LIPTON, R.B.; SILBERSTEIN, M.D.; STEWART, W.F. An update on the epidemiology of migraine. Headache v. 34, P. 319-328, 1994.

LIPTON, R.B.; BIGAL, M.E. Tem Lessons on epidemiology of migraine. Headache, v.47, p.S2-S9,2007.

LIST, T.; HELKIMO, M.; FALK, G. Reliability and validity of pressure threshold meter in recording tenderness in the masseter muscle and the anterior temporalis muscle. Cranio, v. 7, n. 33, p.223-229, 1989.

LOBBEZZO, F.; SELMS, M. K.A.V.; JONH, M.T.; HUGGINS, K.; ORBACH, R.; VISSCHER, C.; ZAAG, J. V. D.; MEULUN, M.J.V.D.; NAEIJE, M.; DWORKIN. S.F. Use 
of the research dianostic criteria for temporomandibular dosorders for multinational research: translation efforts and reability assessment in the Netherlands. J. of Oralfacial Pain, v.19, n.4, p. 301-308, 2005.

MAGNUSSON, T.; EGERMARK,I.; CARLSSON, G.E. A longitudinal epidemiologic study of signs andsymptoms of temporomandibular disorders from 15 to 35 years of age. $\mathbf{J}$. Oralfac. Pain., v.14, p.310-319, 2000.

MOLINA O.F.; SANTOS J.; NELSON S.J.; GROSSMAN E. Prevalence of modalities of headache and bruxism among patients with craniomandibular disorders. The Journal of Craniomandibular Practice, v.15, p.314-325,1997.

MANFREDINI, D.; SEGU, M.; BERTACCI, A.; BINOTTI, G.; BOSCO, M. Diagnosis of temporomandibular disorders according to $\mathrm{RDC} / \mathrm{TMD}$ axis $\mathrm{I}$ finding. Minerva stomatologica, v.55, p.429-38,2004.

MANNHEIMER, J. S.; ROSENTHAL, R.M. Acute and chronic postural abnormalities as related to craniofascial pain and temporomandibular disorders. Dent. Clin. North. AM., v.35, n.1, p. 185-208,1991.

MERRIL, R.L. Orofacial pain mechanisms and their clinical application. Dental Clinical of North America, v.41, p.167-18,1997.

OKESON, J.P. Orofacial pain: guidelines for assessment, diagnosis and management. Quintessence Publishing Co, Inc, Chicago, 1998.

OLIVEIRA, A.S.; BERMUDEZ, C.C.; SOUZA, C.M.F.; CASTRO, C.E.S.; BÉRZIN, F. Avaliação multidimencional da dor em portadores de desordens temporomandibulares uma versão brasielira do questionário Mcgill de dor. Revista Brasileira de Fisioterapia, v.7, n.2, p.151-158, 2003.

OLIVO, S. A.; BRAVO, J.; MAGEE, D. J.; THIE, N.M.R.; FLORES-MIR, C. The association between head and cervical posture and temporomandibular disorders: a systematic review. J. Orofacial pain, v. 20, n.1, p.9-23, 2006.

PEDRONI, C.R.; OLIVEIRA, A.S.; GUARATINI, M.I. prevalence study and symptoms of temporomandibular disorders in university students. J. Oral. Rehabil., v.30, p.283-289,2003.

PETTENGILL, G. A comparison of headache symptoms betwenn two groups: A TMD group and a general dental practice group. The Journal of Craniomandibular Practice, v.17, p.64-69,1999. 
RAMMELSBERG, P.; LERESCHE, L.; DWORKING, S.; MANCL,L. Longtudinal outcome of temporomandibular disorders: a 5- year epidemiologic study of muscle defined by Research Diagnpstic Criteria for Temporomandibular disorders. J. of Oroalfacial Pain. V.17, p.9-20, 2003.

RASKIN, N. H. Headache. 2.ed. new York: churchil livingstone, 1998.

RASMUSSEN, B.K.; JENSEN, R.; SCHROLL, M.; OLESEN, J.; Epidemiology of headache in general population- a prevalence study. Journal of clinical epidemiology, v.44, p.1147115,1991 .

RASMUSSEN, B.K. Epidemiology of headache. Cephalalgia, v.5, p. 45-68, $1995 .$.

RUGH, J.D.; SOLBERG, W.K. Oral health status in the United States: Temporomandibular disorders. J. Dent. Educ., v. 49, p.398-405,1985.

SARLANI, E. Diagnosis end treatment of orofacial pain. Braz. J Oral., v. 2, n.6, p. 283-290, 2003.

SARLANI, E.; GREENSPAN, J.D.Why look in brain for answers to temporomandibular disorers pain? Cells Tissues Organs, v.180. p.69-75, 2005.

SCHOKKER, P.; HANSSON, T.L.; ANSINK, B.J. Craniomandibular disorders in pacients with different types of headache. J Craniomandibular Disord Facial Oral Pain, v.4, p.47$51,1990$.

SCHOKKER, R.P.; HANSSON, T.L.; ANSINK, B.J. Craniomandibular disorders in headache patients. J Craniomandib Disord., v. 3, p.71-74, 1990.

SHER, A.L; STEWART, W.F; RICCI, J.A; LIPTON, R.B. Factores associated with the onset remission of chronic daily headache in a population-based study. Pain, v.6, p.81-88,2003.

SHMITTER, M.; GABBERT, O.; OHLMANN, B.; HASSEL, A.; WOLFF, D.; RAMMELSBERG, P.; ET AL. Assessment of the reliability and validity of panoramic imaging for assessment of mandibular condyle morphology using both MRI and clinical examination as the gold standard. Oral Surg Oral Med Oral Pathol Oral Radiol Endod, v.102, n.2, p.220-224, 2006.

STORM, C.; WANMAN, A. Temporomandibular disorders, headache, and cervical pain among females in a sami population. Acta Odontologica Scandinavica, v.64, p.319-325, 2006. 
SILBERSTEIN, S. D.; LIPTON, R. Headache epidemiology: emphasis on migraine. Neurol Clin V. 14, P. 421-434, 1996.

SPECIALI, J. G. Entendendo a enxaqueca. Ribeirão preto: Editora Funpec, 2003.

STOVNER, L.J. HAGEN, K.; JENSEN, R.; et al. The global burden of headache: A documentation of headache prevalence and disability worldwide. Cephalalgia, v.27, p.193210,2007 .

STUGISNKI-BARBOSA, J.; MACEDO,H.R.; BIGAL, M.E.; SPECIALI, J.G. Signs of Temporomandibular Disorders in Migraine Patients: A Prospective, Controlled Study. Clin J Pain, 2010, in press.

VAN DER WEELE, L.T,; DIBBETS, J.M. Conceptual models for analyzing symptoms of temporomandibular joint dysfunction. Cranio, v. 4, P. 357-66.

VAZQUEZ-DELGADO, E.; SCHMIDT, J,; CARLSON, C,; DELEEUW, R,; OKESON, J. Psychological and sleep quality differences between chronic daily headache and temporomandibular disorders patients. Cephalalgia, v. 24, p. 446-454, 2004.

VISSCHER, C.M.; LOBBEZZO, F.; DE BOER, W.; MEULEN, M.V.; NAEIJE, M. Psychological distress in chronic craniomandibular and cervical spinal pain pacients . European journal of oral sciences, v.109, n.3, p.165-171, 2001.

VISSCHER, C.M.; LOBBEZZO, F.; DE BOER, W.; VAN DER ZAAG, J.; NAEIJE, M. Prevalence of cervical spinal pain in Craniomandibular pain patients. European journal of oral sciences, v.109, p.76-80,2001.

VISSCHER, C.M.; LOBBEZZO, F.;NAEIJE, M. Comparasion of algometry and palpation in the recognition of temporomandibular disorders pain complainst. J. Orofacial Pain, v.18, n.3, p.214-219, 2004.

WEILLER, C.; ET AL. Brain stem activation in spontaneous human migraine attacks. Nature Medicine, v.101, p.658-60, 1995.

WELCH, K.M.A. Drug therapy of migraine. The New England journal of medicine, v.329, p.1476-83, 1993. 


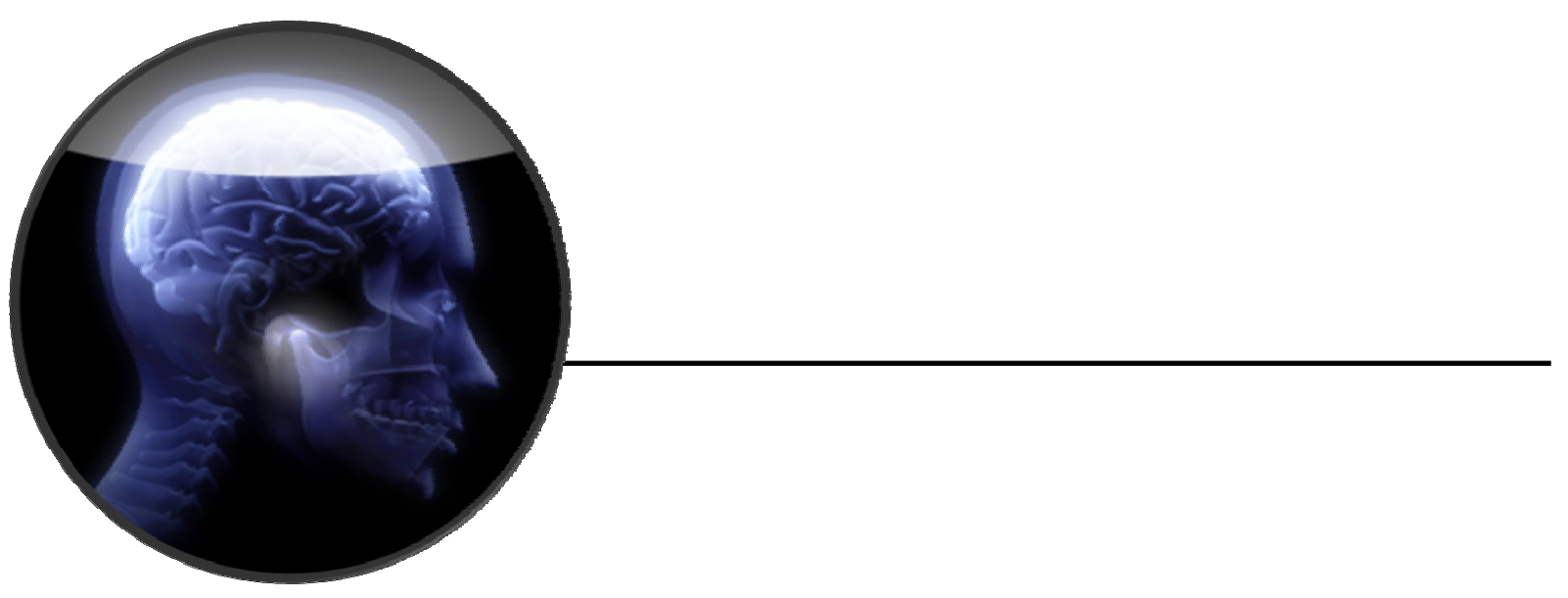

Anexos 


\section{ANEXOS}

ANEXO A

Carta de aprovação do Comitê de Ética em pesquisa do Hospital das Clínicas da Faculdade de Medicina de Ribeirão Preto.

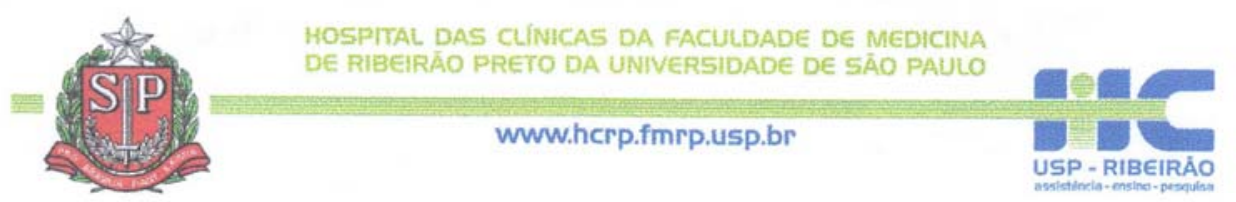

Ribeirão Preto, 20 de junho de 2007.

Oficio $n^{\circ} .2025 / 2007$

CEP/SPC

Prezada Senhora,

O trabalho intitulado "AVALIAÇÃO DO LIMIAR DE DOR POR PRESSÃo dOS MÚSCULOS MASTIGATÓRIOS E CRÂNIO-CERVICAIS EM MULHERES COM CEFALÉIA E SUAS CORRELAÇÕES COM AS DISFUNÇÕES TEMPORAMANDIBULARES", foi analisado pelo Comitê de Ética em Pesquisa e APROVADO “AD REFERENDUM" em 20/06/2007, bem como o Termo de Consentimento Livre e Esclarecido, de acordo com op Processo HCRP n ${ }^{\circ}$ 9663/2006.

Atenciosamente.

PROF. DR. SERRGIO PEREIRA DA CUNHA

Coordenador de Comitê de Ética em Pesquisa do HCRP e da FMRP-USP

Ilustrissima Senhora

MARIA CLÁUDIA GONÇALVES

PROF $^{a}$ DR $^{\text {a }}$ DÉBORA BEVILAQUA GROSSI

Departamento de Biomecânica, Medicina e Reabilitação do Aparelho Locomotor

Comitê de Ética em Pesquisa HC e FMRP-USP - Campus Universitário FWA - 0000 2733; IRB - 00002186

Fone (16) 3602-2228 - E-mail : cep@hcrp.fmrp.usp.br

Monte Alegre 14048-900 Ribeirắo Preto SP 


\section{ANEXO B}

Termo de consentimento Livre e Esclarecido

Eu,

RG

Bairro , Residente à $n^{\mathrm{o}}$ , CEP

Declaro que tenho anos de idade e concordo com a minha participação voluntária na pesquisa conduzida pelos alunos responsáveis e por sua orientadora.

\section{Possíveis benefícios:}

Estou ciente de que não existem benefícios diretos para mim durante a minha participação nesta pesquisa e que os dados obtidos pelos responsáveis pela pesquisa auxiliaram no maior conhecimento a respeito dos problemas relacionados com as dores de cabeça.

\section{Desconforto e risco:}

Fui informado que este experimento não trará nenhum tipo de risco a minha saúde, poderá causar um pequeno desconforto através da palpação dos músculos do meu rosto e minha identidade será mantida em segredo absoluto.

\section{Seguro de vida:}

Eu entendo que não existe nenhum tipo de seguro de saúde ou de vida que possa me beneficiar em função da participação neste estudo.

\section{Liberdade de participação:}

A minha participação neste estudo depende plenamente da minha autorização. É meu direito interromper a minha participação a qualquer momento sem que isso incorra em qualquer penalidade ou juízo contra mim. Também entende que os pesquisadores deste estudo tem o direito de não utilizarem os meus dados caso eu abandone a pesquisa ou não colabore durante o período de exame.

\section{Sigilo de identidade:}

As informações obtidas nessa pesquisa não serão de maneira alguma associadas à minha identidade e não poderão ser consultadas por pessoas leigas sem minha autorização oficial. Essas informações poderão ser utilizadas para fins estatísticos ou científicos, desde de que fiquem resguardado minha privacidade e meu anonimato.

Os responsáveis pelo estudo me explicaram todo o exame que serei submetido, a necessidade da pesquisa e se prontificaram a responder todas as dúvidas sobre a pesquisa. Eu aceitei participar desde estudo de livre e espontânea vontade. Entendo que é meu direito manter uma cópia deste consentimento.

Assinatura do voluntário

Ribeirão Preto, de
Assinatura do pesquisador de 200

Para questões sobre este estudo, contatar:

Profa. Dr. Débora Bevilaqua Grossi

Curso de Fisioterapia da Faculdade de Medicina de Ribeirão Preto - FMRP

Universidade de São Paulo - USP Fone: (16) 3602-4413

e_mail:deborabg@fmrp.usp.br 


\section{ANEXO C}

Versão adaptada do Índice Anamnésico de Fonseca para Avaliação da Disfunção Temporomandibular (FONSECA et al., 1994).

\begin{tabular}{|l|l|l|l|}
\hline \multicolumn{1}{|c|}{ Perguntas } & $\begin{array}{c}\text { Sim } \\
\text { (10) }\end{array}$ & $\begin{array}{c}\text { Não } \\
\text { (0) }\end{array}$ & $\begin{array}{c}\text { Às vezes } \\
\text { (5) }\end{array}$ \\
\hline $\begin{array}{l}\text { 1.Sente dificuldade para abrir a boca? } \\
\text { p/D p/D e E }\end{array}$ & & & \\
\hline $\begin{array}{l}\text { 2. Você sente dificuldade para movimentar sua } \\
\text { mandíbula para os lados? }\end{array}$ & & & \\
\hline $\begin{array}{l}\text { 3. Tem cansaço/dor muscular quando mastiga? } \\
\text { 4. Sente dor na nuca ou torcicolo? }\end{array}$ & & & \\
\hline $\begin{array}{l}\text { 5. Tem dor no ouvido ou na região das articulações } \\
\text { perto do ouvido (ATMs)? }\end{array}$ & & & \\
\hline $\begin{array}{l}\text { 6. Já notou se tem ruído nas ATMs quando mastiga ou } \\
\text { quando abre a boca? }\end{array}$ & & & \\
\hline $\begin{array}{l}\text { 7. Você já observou se tem algum hábito como apertar } \\
\text { ou ranger os dentes? }\end{array}$ & & & \\
\hline 8. Sente que seus dentes não articulam bem? & & & \\
\hline 9. Você se considera uma pessoa tensa (nervosa) & & & \\
\hline
\end{tabular}




\section{ANEXO D}

RDC/TMD - Critérios de Diagnóstico em Pesquisa para DTM

Idade_Sexo__ Raça__ Série

Você tem algum desses sintomas:

Estalo

Ranger

Rangido noturno

Rangido diurno

Mordida desconfortável/fora do usual

Rigidez matinal

Barulho no ouvido

$\begin{array}{ll}\text { sim } & \text { não } \\ \operatorname{sim} & \text { não } \\ \operatorname{sim} & \text { não } \\ \operatorname{sim} & \text { não } \\ \operatorname{sim} & \text { não } \\ \operatorname{sim} & \text { não } \\ \operatorname{sim} & \text { não }\end{array}$

\section{História - Questionário}

3. Você já teve dor na face, nos maxilares, têmpora, na frente do ouvido, ou no ouvido no MÊS PASSADO?

$$
\text { Não } \quad 0 \quad \text { Sim } 1
$$

14.a. Você alguma vez teve travamento articular de forma que não foi possível abrir a boca por todo o trajeto ?

$$
\text { Não } \quad 0 \quad \text { Sim } 1
$$

[se nunca apresentou este tipo de problema, PULE para a pergunta 16]

\section{Se a sua resposta foi $\underline{\operatorname{Sim}}$,}

14.b. Esta limitação de abertura mandibular foi severa a ponto de interferir com a sua capacidade de mastigar?

$$
\text { Não } 0 \quad \text { Sim } 1
$$

16.c. Você já apresentou ou apresenta inchaço ou dor em qualquer das articulações que não sejam as articulações perto dos seus ouvidos (ATM)?

Se a sua resposta foi $\underline{\mathrm{Sim}}$,

$$
\text { Não } \quad 0 \quad \text { Sim } 1
$$

16.d. É uma dor persistente que você vem tendo por pelo menos um ano ?

$$
\text { Não } \quad 0 \quad \text { Sim } 1
$$




\section{Formulário de Exame}

1. Você tem dor no lado direito da sua face, lado esquerdo ou ambos os lados ?

Em nenhum dos lados $0 \quad$ No lado direito $1 \quad$ No lado esquerdo $2 \quad$ Em ambos os lados 3

2. Você poderia apontar as áreas aonde você sente dor ?

\begin{tabular}{|l|l|l|c|}
\hline Direito & \multicolumn{2}{|l|}{ Esquerdo } \\
\hline Nenhuma & 0 & Nenhuma & 0 \\
\hline Articulação & 1 & Articulação & 1 \\
\hline Músculos & 2 & Músculos & 2 \\
\hline Ambos & 3 & Ambos & 3 \\
\hline
\end{tabular}

Examinador deve apalpar a área apontada pelo paciente, caso não esteja claro se é dor muscular ou articular

\section{Padrão de Abertura}

Sem desvio

Desvio lateral direito (não corrigido)

Desvio lateral direito corrigido ("S")

Desvio lateral esquerdo (não corrigido)

Desvio lateral corrigido ("S")

Outro

Tipo

$$
\text { (especifique) }
$$

4. Amplitude de movimento de Abertura da boca

Você tem dor durante abertura da boca? Não 0

$\operatorname{Sim} 1$
a. Abertura passiva sem dor $\mathrm{mm}$
b. Abertura máxima passiva $\mathrm{mm}$
c. Abertura máxima ativa $\mathrm{mm}$
d. Overbite $\mathrm{mm}$

Tabela abaixo: Para os itens " $b$ " $e$ " $c$ " somente

\begin{tabular}{|c|c|c|c|c|c|c|c|c|}
\hline & \multicolumn{4}{|c|}{ Dor Muscular } & \multicolumn{4}{c|}{ Dor Articular } \\
\hline itens & nenhuma & direito & esquerdo & ambos & nenhuma & direito & esquerdo & ambos \\
\hline b & 0 & 1 & 2 & 3 & 0 & 1 & 2 & 3 \\
\hline c & 0 & 1 & 2 & 3 & 0 & 1 & 2 & 3 \\
\hline
\end{tabular}

5. Ruídos articulares (palpação)

a. abertura

Nenhum
Estalido
Crepitação grosseira
Crepitação fina

$$
\text { Direito }
$$$$
\text { Esquerdo }
$$

$$
0
$$

Crepitação grosseira

Crepitação fina 
b. Fechamento

Nenhum

Estalido

Crepitação grosseira

Crepitação fina

$\begin{array}{cc}\text { Direito } & \text { Esquerdo } \\ 0 & 0 \\ 1 & 1 \\ 2 & 2 \\ 3 & 3\end{array}$

Medida do estalido de fechamento $\mathrm{mm}$ $\mathrm{mm}$

c. Estalido recíproco eliminado durante abertura protrusiva (NA: não apresenta)

$\operatorname{Sim}$

Não

NA

Direito

0

Esquerdo

1

1

8

8

6. Excursões

Você tem dor durante os desvios laterais?

a. Desvio lateral direito

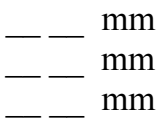

b. Desvio lateral esquerdo

- $-\mathrm{mm}$

c. Protrusão

Dor articular

\begin{tabular}{|c|c|c|c|c|c|c|c|c|}
\hline & \multicolumn{4}{|c|}{ Dor muscular } & \multicolumn{4}{c|}{ Dor articular } \\
\hline itens & nenhuma & direito & esquerdo & ambos & nenhuma & direito & esquerdo & ambos \\
\hline a) & 0 & 1 & 2 & 3 & 0 & 1 & 2 & 3 \\
\hline b) & 0 & 1 & 2 & 3 & 0 & 1 & 2 & 3 \\
\hline c) & 0 & 1 & 2 & 3 & 0 & 1 & 2 & 3 \\
\hline
\end{tabular}

d. Desvio de linha média $\mathrm{mm}$

\begin{tabular}{|c|c|c|}
\hline direito & esquerdo & NA \\
\hline 1 & 2 & 8 \\
\hline
\end{tabular}

NA - não apresenta

7. Ruídos articulares nas excursões

Ruídos lado direito

\begin{tabular}{|l|c|c|c|c|}
\hline & nenhum & estalido & $\begin{array}{l}\text { Crepitação } \\
\text { grosseira }\end{array}$ & $\begin{array}{l}\text { Crepitação } \\
\text { leve }\end{array}$ \\
\hline Excursão Direita & 0 & 1 & 2 & 3 \\
\hline Excursão Esquerda & 0 & 1 & 2 & 3 \\
\hline Protrusão & 0 & 1 & 2 & 3 \\
\hline
\end{tabular}

Ruídos lado esquerdo

\begin{tabular}{|l|c|c|c|c|}
\hline & nenhuma & estalido & $\begin{array}{l}\text { Crepitação } \\
\text { grosseira }\end{array}$ & $\begin{array}{l}\text { Crepitação } \\
\text { leve }\end{array}$ \\
\hline Excursão Direita & 0 & 1 & 2 & 3 \\
\hline Excursão Esquerda & 0 & 1 & 2 & 3 \\
\hline Protrusão & 0 & 1 & 2 & 3 \\
\hline
\end{tabular}




\section{INSTRUÇÕES, ÍTENS 8-10}

\section{Dor muscular extra-oral com palpação}

\begin{tabular}{|l|c|c|}
\hline & \multicolumn{2}{|c|}{ EVA } \\
\hline & Direito & Esquerdo \\
\hline a. Temporal anterior & & \\
\hline b. Temporal Médio & & \\
\hline c. Temporal posterior & & \\
\hline d. Origem do masseter & & \\
\hline e. Ventre do masseter & & \\
\hline f. Inserção do masseter & & \\
\hline g. Região posterior da mandíbula (estilo-hióide/região posterior do digástrico) & & \\
\hline h. Região submandibular (pterigóide medial/supra-hióide/região anterior do digástrico) & & \\
\hline
\end{tabular}

9. Dor articular com palpação

a. Pólo lateral da ATM

b. Pólo posterior da ATM

10. Dor muscular intra-oral com palpação

a. Área do Pterigóideo lateral

b. Tendão do temporal

$\underline{\text { Resumo dos achados subjetivos do paciente }}$

\section{Diagnóstico Eixo I}

Grupo I. Desordem muscular (circule somente uma resposta para grupo I):

a) Dor miofascial (Ia): H3, AC: 1, 8, 10

b) Dor miofascial com abertura limitada (Ib): AC 4a, 4 c, 4d

c) Nenhum diagnóstico do grupo I

Grupo II. Deslocamento discal (circule somente uma resposta para cada articulação no grupo II):

\begin{tabular}{|c|c|c|c|}
\hline Articulacão direita & Itens & ATM D & ATM E \\
\hline a) Deslocamento do disco com redução (II a). & AC $5 \mathrm{a}, 5 \mathrm{~b}, 7$ & & \\
\hline $\begin{array}{l}\text { b) Deslocamento do disco sem redução, com limitação } \\
\text { da abertura (II b). }\end{array}$ & $\begin{array}{l}\mathrm{H} 14, \mathrm{AC} \text { e }, 6^{\mathrm{a}}, 6 \mathrm{~b}, 6 \mathrm{~d} \\
4 \mathrm{~b}, 4 \mathrm{c}, 4 \mathrm{~d}, 5,7\end{array}$ & & \\
\hline $\begin{array}{l}\text { c) Deslocamento do disco sem redução, sem limitação } \\
\text { da abertura (II c). }\end{array}$ & $\begin{array}{l}\text { H14, 4b, 4c, 4d, 5, 6a, } \\
\text { 6b, 6d, 7 + RNM } \\
\end{array}$ & & \\
\hline $\begin{array}{l}\text { d) Nenhum diagnostico da articulação direita no grupo } \\
\text { II. }\end{array}$ & & & \\
\hline
\end{tabular}

Grupo III. Outras condições articulares (circule somente uma resposta para cada articulação no grupo III):

\begin{tabular}{|l|c|c|c|}
\hline \multicolumn{1}{|c|}{ Articulação direita } & Itens & ATM D & ATM E \\
\hline a) Artralgia (IIIa) & $\begin{array}{c}\text { AC 2, 9, 4b, 4c, 4d, 5, } \\
6 \mathrm{a}, 6 \mathrm{~b}, 7\end{array}$ & \\
\hline b) Osteoartrite da ATM (IIIb) & $\begin{array}{c}\text { Artralgia + AC 5, 7 + } \\
\text { crepitação }\end{array}$ & \\
\hline c) Osteoartrose da ATM (IIIc) & $\begin{array}{c}\text { Sem Altralgia + AC 5, } \\
7+\text { crepitação }\end{array}$ & \\
\hline $\begin{array}{l}\text { d) Nenhum diagnóstico da articulação esquerda no grupo } \\
\text { III. }\end{array}$ & & & \\
\hline
\end{tabular}

